\title{
Septal Projections to Nucleus Incertus in the Rat: Bidirectional Pathways for Modulation of Hippocampal Function
}

\author{
Ana M. Sánchez-Pérez, ${ }^{1}$ Isabel Arnal-Vicente, ${ }^{2}$ Fabio N. Santos, ${ }^{3}$ Celia W. Pereira, ${ }^{3}$ Nisrin EIMlili, ${ }^{4}$ \\ Julio Sanjuan, ${ }^{5}$ Sherie Ma, ${ }^{6,7}$ Andrew L. Gundlach, ${ }^{6,7,8}$ and Francisco E. Olucha-Bordonau ${ }^{1,2 *}$ \\ ${ }^{1}$ Departamento de Medicina, Universitat Jaume I, 12071 Castellón, Spain \\ ${ }^{2}$ CIBERSAM, INCLIVA, Departamento de Anatomía y Embriología Humana, Facultad de Medicina, Universidad de Valencia, 46010 \\ Valencia, Spain \\ ${ }^{3}$ Departmento de Fisiologia, Universidade Federal de Sergipe, 49060 Aracaju, Brasil \\ ${ }^{4}$ Institut de Formation aux Carrières de Santé de Rabat, 10000 Rabat, Morocco \\ ${ }^{5}$ CIBERSAM, INCLIVA, Departamento de Medicina, Facultad de Medicina, Universidad de Valencia, 46010 Valencia, Spain \\ ${ }^{6}$ Florey Institute of Neuroscience and Mental Health, University of Melbourne, Parkville, Victoria 3052, Australia \\ ${ }^{7}$ Florey Department of Neuroscience and Mental Health, University of Melbourne, Victoria 3010, Australia \\ ${ }^{8}$ Department of Anatomy and Neuroscience, University of Melbourne, Victoria 3010, Australia
}

\begin{abstract}
Projections from the nucleus incertus $(\mathrm{NI})$ to the septum have been implicated in the modulation of hippocampal theta rhythm. In this study we describe a previously uncharacterized projection from the septum to the $\mathrm{NI}$, which may provide feedback modulation of the ascending circuitry. Fluorogold injections into the $\mathrm{NI}$ resulted in retrograde labeling in the septum that was concentrated in the horizontal diagonal band and areas of the posterior septum including the septofimbrial and triangular septal nuclei. Double-immunofluorescent staining indicated that the majority of NI-projecting septal neurons were calretinin-positive and some were parvalbumin-, calbindin-, or glutamic acid decarboxylase (GAD)-67-positive. Choline acetyltransferase-positive neurons were Fluorogold-negative. Injection of anterograde tracers into medial septum, or triangular septal and septofimbrial nuclei, revealed fibers descending to the supramammil-
\end{abstract}

lary nucleus, median raphe, and the NI. These anterogradely labeled varicosities displayed synaptophysin immunoreactivity, indicating septal inputs form synapses on $\mathrm{NI}$ neurons. Anterograde tracer also colocalized with GAD-67-positive puncta in labeled fibers, which in some cases made close synaptic contact with GAD-67-labeled $\mathrm{NI}$ neurons. These data provide evidence for the existence of an inhibitory descending projection from medial and posterior septum to the $\mathrm{NI}$ that provides a "feedback loop" to modulate the comparatively more dense ascending $\mathrm{NI}$ projections to medial septum and hippocampus. Neural processes and associated behaviors activated or modulated by changes in hippocampal theta rhythm may depend on reciprocal connections between ascending and descending pathways rather than on unidirectional regulation via the medial septum. J. Comp. Neurol. 523:565-588, 2015.

(C) 2014 Wiley Periodicals, Inc.

INDEXING TERMS: nucleus incertus; septohippocampal system; theta rhythm; GABA; calretinin; anxiety; spatial and emotional learning; arousal

\footnotetext{
Additional Supporting Information may be found in the online version of this article.

Grant sponsors: Fundación Alicia Koplowitz Fellowship (to A.M.S.P.), CAPES-Brasil Bex - 4494/09-1 (to F.N.S.) and 4496/09-4 (to C.W.P.) and Fapitec edital \#01/08 (to F.N.S.), FIS-isciiiPI10/01399 (to J.S.), National Health and Medical Research Council of Australia - 520299 (to S.M.), 509246, 1005985, and 1005988 (to A.L.G.), the Florey Foundation (to S.M., A.L.G.), Besen Family Foundation (to A.L.G.) and a NEUREN project, FP7-PEOPLE-IRSES PIRSES-GA-2012-318997 (to A.L.G., F.E.O.-B.).

The first two authors contributed equally to this work.

*CORRESPONDENCE TO: Francisco E. Olucha-Bordonau, Departamento de Medicina, Universitat Jaume I, 12071 Castellón, Spain. E-mail olucha@uv.es

Received May 31, 2014; Revised September 26, 2014; Accepted September 26, 2014.

DOI $10.1002 / c n e .23687$

Published online September 30, 2014 in Wiley Online Library (wileyonlinelibrary.com) 
Arousal processes initiate adaptation to changes in environmental conditions. Following research on the general mechanisms of arousal that began with early studies to identify an ascending system arising from the brainstem reticular formation (Moruzzi and Magoun, 1995), it is generally accepted that widespread activation of telencephalic centers drives awakening and awareness.

The septal area has been traditionally viewed as an interface connecting the so-called "limbic telencephalon" with the hypothalamus and brainstem. This concept arose from the observation of a complementary pattern of neural connections for the medial and lateral septum. In a simplified view, while the medial septum/diagonal band complex (MS/DB) receives ascending projections from the diencephalon and brainstem, and this neural information is generally relayed to the hippocampus, cortex, and amygdala (Vertes and Kocsis, 1997), the lateral septum receives inputs from the hippocampus, which are relayed to the hypothalamus and brainstem (Risold and Swanson, 1997a; Leranth and Vertes, 1999). As a consequence of this view, physiological studies of the MS/DB have centered on its role in driving hippocampal activity, particularly theta rhythm, an oscillatory neural activity believed to underlie mnemonic processing (e.g., Kesner et al., 1986; Cahill and Baxter, 2001; Dwyer et al., 2007). Electrolytic lesions of the MS result in impaired hippocampal theta rhythm (Petsche and Stumpf, 1962; Winson, 1978; Sainsbury and Bland, 1981). Specific lesions of either GABAergic or cholinergic septal neurons produce a decrease in theta power (Lee et al., 1994; Apartis et al., 1998; Yoder and Pang, 2005) and studies in freely moving rats demonstrate that the integrity of the entire medial and lateral septumhippocampal network is critical for theta rhythmogenesis (Nerad and McNaughton, 2006).
MS/DB neurons display differential actions in the control of hippocampal activity. Slow-firing cholinergic neurons appear to facilitate hippocampal activity (Sotty et al., 2003), while fast-firing, parvalbumin (PV)-containing GABAergic neurons, innervate hippocampal interneurons mediating disinhibition of pyramidal and granule cells (Freund and Antal, 1988; Freund and Gulyas, 1997; Toth et al., 1997; Hangya et al., 2009). Slow-firing neurons are associated with transient arousal and may function to promote hippocampal activation (Zhang et al., 2011). Thus, these facilitatory and disinhibitory actions promote hippocampal synchrony at theta frequency (Freund and Antal, 1988). Specific lesions of GABAergic or cholinergic MS/DB neurons reveal that both neural populations contribute to hippocampal theta (Yoder and Pang, 2005), and inhibitory neurons within the hippocampus can induce rhythmic firing of GABAergic septal neurons, which in turn generates hippocampal theta (Manseau et al., 2008).

The nucleus incertus (NI) in the midline tegmentum sends an array of ascending projections to the septal area (Goto et al., 2001; Olucha-Bordonau et al., 2003), and we have shown that stimulation of the $\mathrm{NI}$ in urethane-anesthetized rats increased theta and decreased delta activity within the hippocampus (Nunez et al., 2006). In contrast, electrolytic lesion of the NI abolished hippocampal theta induced by stimulation of the nucleus reticularis pontis oralis (RPO) (Nunez et al., 2006), a key brainstem generator of hippocampal theta rhythm (Vertes, 1981, 1982; Vertes et al., 1993). The dorsal hippocampus receives only sparse inputs from the NI (Goto et al., 2001; Olucha-Bordonau et al., 2003), suggesting that the influence of the NI on hippocampal theta rhythm is more likely mediated by its dense projections to the MS/DB. NI neurons are largely

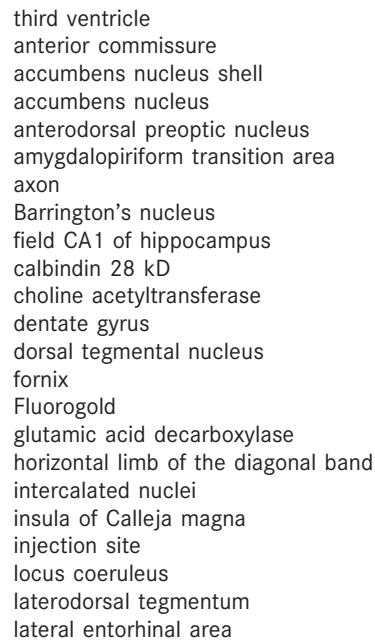

Abbreviations

$\begin{array}{ll}\text { LSD } & \text { lateral septum, dorsal } \\ \text { LSI } & \text { lateral septum, intermediate } \\ \text { LSV } & \text { lateral septum, ventral } \\ \text { mIf } & \text { medial longitudinal fasciclus } \\ \text { MnPO } & \text { median preoptic nucleus } \\ \text { MPA } & \text { medial preoptic area } \\ \text { mR } & \text { miniruby } \\ \text { NIc } & \text { nucleus incertus pars compacta } \\ \text { NId } & \text { nucleus incertus pars dissipata } \\ \text { Oc } & \text { optic chiasma } \\ \text { PDTg } & \text { posterodorsal tegmental nucleus } \\ \text { PDZ } & \text { paradiagonal zone } \\ \text { Pe } & \text { periventricular hypothalamic nucleus } \\ \text { PV } & \text { parvalbumin } \\ \text { S } & \text { subiculum } \\ \text { SFi } & \text { septofimbrial nucleus } \\ \text { SHi } & \text { septohippocampal nucleus } \\ \text { SHy } & \text { septohypothalamic nucleus } \\ \text { SIB } & \text { substantia innominata, basal part } \\ \text { ST } & \text { bed nucleus of the stria terminalis } \\ \text { Syn } & \text { synaptophysin } \\ \text { TS } & \text { triangular septal nucleus } \\ \text { VDB } & \text { vertical limb of the diagonal band }\end{array}$


glutamic acid decarboxylase (GAD)-67-positive (OluchaBordonau et al., 2003), and relaxin-3 is thought to be coreleased with GABA from $\mathrm{NI}$ neurons in the rat (Tanaka et al., 2005; Ma et al., 2007), mouse (Smith et al., 2010), and Macaca fascicularis (Ma et al., 2009b). This peptide is considered a marker for $\mathrm{NI}$, since the distribution of fibers containing relaxin-3 (Ma et al., 2007) is generally consistent with that of $\mathrm{NI}$ projections (Goto et al., 2001; Olucha-Bordonau et al., 2003), particularly in the MS, which is one of the most highly innervated telencephalic targets of this nucleus (Ma et al., 2009a; Olucha-Bordonau et al., 2011). In a functional context, infusion of a relaxin-3 receptor (RXFP3) agonist peptide into the MS/DB increased hippocampal theta activity in urethane-anesthetized and awake rats, an effect blocked by prior infusion of an RXFP3 antagonist (Ma et al., 2009b). Furthermore, RXFP3 antagonist injection into the MS/DB significantly blunted RPO-stimulated hippocampal theta activity in anesthetized rats and novelty-induced hippocampal theta activity in awake, freely moving rats, and resulted in dose-related impairment of spatial working memory (Ma et al., 2009b). These findings suggest that relaxin-3 is a potentially important mediator of $\mathrm{NI}$ influence on the septohippocampal system (Ryan et al., 2011; Ma et al., 2013).

Although there have been earlier studies characterizing the ascending connections of the $\mathrm{NI}$ to the septohippocampal system (e.g., Olucha-Bordonau et al., 2012), little is known regarding the afferent inputs of the $\mathrm{NI}$, other than initial connectivity mapping in rat brain (Goto et al., 2001). The MS/DB is known to have both ascending connections to the hippocampus and descending connections to different hypothalamic and brainstem nuclei (Swanson and Cowan, 1979; Krayniak et al., 1980; Wouterlood et al., 1988; Cornwall et al., 1990). Thus, we hypothesized that a projection from the MS/DB to the $\mathrm{NI}$ may complete the network subserving the modulation of hippocampal theta rhythm.

The goal of this study, therefore, was to characterize septal afferent projections to the NI. Using retrograde labeling, we identified that discrete populations of neurons in the horizontal diagonal band (HDB) as well as triangular septal and septofimbrial nuclei project to the $\mathrm{Nl}$; these neurons are distinct from the choline acetyltransferase (ChAT)-positive septal neurons projecting to hippocampus and different from the GAD/PV neurons projecting to hippocampus. We observed that the majority of septo-NI neurons are calretinin-positive. In addition, we used anterograde labeling from the septal area to confirm the existence of these dispersed but consistently observed septal to NI projections. Some of these anterogradely labeled fibers contained synaptophysin, suggesting that fibers from the septal area form synapses within
NI. Also, some of these fibers were observed in close contact with GAD-67-positive neurons. Thus, using a combination of retrograde tracing from the $\mathrm{NI}$ and anterograde tracing from septum, we determined the existence and nature of septal projections to the NI which potentially modulate ascending $\mathrm{NI}$ projections to the septohippocampal system. Demonstrating the existence of such projections provides a new anatomical basis for determining the functional roles of septohippocampal and hippocamposeptal circuits in theta generation and modulation.

\section{MATERIALS AND METHODS}

\section{Animals}

Male Sprague-Dawley rats (300-400 g, $n=28$ ) were used in this study. All protocols were approved by the Animal Ethics Committee of the Universitat de València (València, Spain). All procedures were in line with directive $86 / 609 /$ EEC of the European Community on the protection of animals used for experimental and other scientific purposes. Details of the experimental protocols employed are provided in Table 1.

\section{Septal anatomy and terminology}

We adopted the terminology used in the 7th Edition of the Paxinos and Watson (2014) Atlas of Rat Brain in Stereotaxic Coordinates. Three main divisions can be identified: the lateral, medial, and posterior septum. The lateral septum (LS) can be subdivided into dorsal (LSD), intermediate (LSI), and ventral (LSV) nuclei. The medial division can be subdivided into three nuclei that are arranged from dorsal to ventromedial and from there to ventrolateral: the medial septum nucleus (MS), vertical diagonal band nucleus (VDB), and horizontal diagonal band nucleus (HDB). A few small nuclei appear in the zone between the medial and lateral divisions of the septum. These nuclei comprise the lambdoid nucleus and the septohippocampal nuclei dorsally, and the paradiagonal zone (PDZ), basal division of the substantia innominata (SIB), and septohypothalamic nucleus (SHy) ventrally. Finally, at caudal levels corresponding to the area also known as the posterior septum (Risold, 2004), the septofimbrial (SFi) nucleus exists as a paired nucleus containing neurons arranged in bands between the bundles of the septal fimbria, while medially, the triangularis septalis (TS) is an unpaired structure occupying the central area of the posterior septum.

\section{Tracer injections}

Rats were anesthetized with ketamine (Imalgene $55 \mathrm{mg} / \mathrm{kg}$ intraperitoneally [i.p.]; Merial Laboratorios, Barcelona, Spain) and xylacide (Xilagesic $20 \mathrm{mg} / \mathrm{kg}$ i.p.; Lab Calier, Barcelona, Spain) and trephine holes were drilled in the skull based on stereotaxic coordinates 
TABLE 1.

Neural Tracer Treatments of Rats and Immunohistochemistry Studies Analyzed

\begin{tabular}{|c|c|c|}
\hline Case & Tracer injection & Immunohistochemistry analysis \\
\hline $\begin{array}{l}\mathrm{CCH} 5 \\
\mathrm{CCH} 11 \\
\mathrm{RS} 31 \\
\mathrm{RS} 29\end{array}$ & Restricted FG injection in NI & $\begin{array}{l}\text { FG tracer analysis and immunofluorescence } \\
\text { for ChAT, PV, GAD-67 and CB28K }\end{array}$ \\
\hline $\begin{array}{l}\mathrm{CCH} 12 \\
\text { RS26 } \\
\text { RS27 }\end{array}$ & FG and reticular formation & FG tracer analysis \\
\hline $\begin{array}{l}\mathrm{CCH} 8 \\
\mathrm{CCH} 10\end{array}$ & $\begin{array}{l}\text { FG in reticular formation. } \\
\text { No diffusion to } \mathrm{NI}\end{array}$ & FG tracer analysis \\
\hline $\begin{array}{l}\text { RS2 } \\
\text { HAl4 } \\
\text { HAl6 } \\
\text { RS5 } \\
\text { RS6 } \\
\text { RS } 10 \\
\text { RS16 }\end{array}$ & $\begin{array}{l}\mathrm{mR} \text { MS/DB } \\
\text { FG hippocampus }\end{array}$ & Confocal $\mathrm{mR}$ and FG tracer analysis \\
\hline $\begin{array}{l}\text { RS } 18 \\
\text { RS } 19 \\
\text { RS23 } \\
\text { RS30 }\end{array}$ & $\mathrm{mR} \mathrm{MS} / \mathrm{DB}$ & $\begin{array}{l}\text { Confocal mR and GAD67 and } \\
\text { synaptophysin immunofluorescence }\end{array}$ \\
\hline $\begin{array}{l}\text { RS47 } \\
\text { S62 }\end{array}$ & BDA HDB & $\begin{array}{l}\text { Anterograde labeling } \\
\text { Anterograde Jabeling }\end{array}$ \\
\hline $\begin{array}{l}\text { LS61 } \\
\text { LS64 }\end{array}$ & BDA SFi & Anterograde labeling \\
\hline $\begin{array}{l}\text { LS63 } \\
\text { LS65 }\end{array}$ & BDA TS & Anterograde labeling \\
\hline $\begin{array}{l}\text { RS15 } \\
\text { RS7 }\end{array}$ & $\mathrm{mR} L S$ & Anterograde labeling from the LS \\
\hline
\end{tabular}

from the atlas of Paxinos and Watson (2014). Anterograde tracer injections of either $15 \%$ miniruby $(\mathrm{mR}, 10$ kD biotinylated dextran amine rhodamine-labeled, Cat. No. D-3312, Molecular Probes, Paisley, UK) or 10\% kD biotinylated dextran amine (BDA, Cat. No. D1956, Molecular Probes, Eugene, OR) dissolved in $0.1 \mathrm{M}$ phosphate buffer (PB), pH 7.6, were iontophoretically delivered via a $40 \mu \mathrm{m}$ I.D. glass micropipette lowered into the MS (AP 0.2 to $-0.4 \mathrm{~mm}, \mathrm{ML} 0.2$ to $0.8 \mathrm{~mm}$, DV -7 to $-8 \mathrm{~mm}$ from bregma) or posterior septum (AP 0.2 to $-0.5 \mathrm{~mm}$, ML 0.4 to $0.8 \mathrm{~mm}$, DV -4.4 to $-6 \mathrm{~mm}$ from bregma) by passing positive current of $1 \mu \mathrm{A}, 2$ seconds on, 2 seconds off for 20 minutes. The micropipette was left in place for an additional 10 minutes before withdrawal. Injections of $4 \%$ Fluorogold retrograde tracer (FG, 5-hydroxystilbamidine, Cat. No 80014 , Biotium, Hayward, CA) dissolved in distilled water were made into the hippocampus (AP $-5.4 \mathrm{~mm}$, ML $5 \mathrm{~mm}$, DV $5 \mathrm{~mm}$ from bregma), NI (AP $-9.6 \mathrm{~mm}, \mathrm{ML} 0 \pm 0.2 \mathrm{~mm}$, DV $7.4 \mathrm{~mm}$ from bregma). Volumes of $40-80 \mathrm{nl}$ were injected using a $40 \mu \mathrm{m}$ I.D. glass micropipette attached to an IM-300 microinjector (Narishige, Tokyo, Japan) over 10 minutes. The wound was sutured and rats were treated with Buprex (0.05 mg/kg, i.p., Lab Esteve, Barcelona, Spain) for analgesia and allowed to recover for at least 7 days.

\section{Brain fixation and sectioning}

For analysis of tracing studies, rats were deeply anesthetized with Nembutal $(150 \mathrm{mg} / \mathrm{kg}$ i.p., Euthalender, Barcelona, Spain) and transcardially perfused with saline $(250 \mathrm{ml})$ followed by fixative (4\% paraformaldehyde in $0.1 \mathrm{M} \mathrm{PB}, \mathrm{pH} 7.4$ ) for 30 minutes $(\sim 500 \mathrm{ml})$. Brains were dissected and immersed in the same fixative for 4 hours at $4^{\circ} \mathrm{C}$. They were then incubated in $30 \%$ sucrose in $0.01 \mathrm{M}$ phosphate-buffered saline (PBS), $\mathrm{pH} 7.4$, for 48 hours at $4^{\circ} \mathrm{C}$. The brains were blocked coronally at the level of the cerebellar flocculi using a rat brain methacrylate matrix (World Precision Instruments, Sarasota, FL) to obtain reliable sections of equivalent orientation from each rat. Free-floating coronal sections $(40 \mu \mathrm{m})$ through the rostral to caudal extent of the septum were collected using a freezing slide microtome (Leica SM2010R, Leica Microsystems, Heidelberg, Germany). For each brain six series of sections were obtained.

\section{Immunofluorescent detection of retrograde tracing and neuronal markers in MS}

For detection of FG and septal marker proteins, sections were rinsed $2 \times 10$ minutes and immersed in a blocking media of Tris-buffered saline (TBS) containing 
TABLE 2.

Primary Antibodies Used in Immunoperoxidase and Immunofluorescence Staining

\begin{tabular}{|c|c|c|c|}
\hline Antigen & Immunogen (MW) & $\begin{array}{l}\text { Manufacturer, Host species, Ig isotype, } \\
\text { Catalog number and RRIDs }\end{array}$ & $\begin{array}{l}\text { Dilution used } \\
\text { in IHC/IF }\end{array}$ \\
\hline Fluorogold & Fluorogold (5-hydroxystabilamide) & $\begin{array}{l}\text { Chemicon, Temecula CA, rabbit, polyclonal, } \\
\text { AB-153, RRID: AB_90738 }\end{array}$ & IHC: $1: 3,000$ \\
\hline ChAT & choline acetyltransferase (70 kD) & $\begin{array}{l}\text { Chemicon, Temecula CA, goat, polyclonal, RRID: } \\
\text { AB_144 }\end{array}$ & IF: $1: 500$ \\
\hline CB-28kD & Chicken calbindin D-28k (28 kD) & $\begin{array}{l}\text { Swant, Bellinzona, Switzerland, mouse, monoclonal, } \\
\text { McAB300, RRID: AB_10000340 }\end{array}$ & IF: $1: 5,000$ \\
\hline PV & parvalbumin (12 kD) & $\begin{array}{l}\text { Swant, Bellinzona, Switzerland, mouse, monoclonal, } \\
\text { McAB235, RRID: AB_10000343 }\end{array}$ & IF: $1: 5,000$ \\
\hline CR & Calretinin & $\begin{array}{l}\text { Swant, Bellinzona, Switzerland, mouse, monoclonal, } \\
\text { 6B3, RRID: AB_10000320 }\end{array}$ & IF $1: 2,500$ \\
\hline GAD-67 & recombinant GAD-67 (67 kD) & $\begin{array}{l}\text { Chemicon, Temecula, CA, mouse, monoclonal, } \\
\text { MAB-5406, RRID: AB_2278725 }\end{array}$ & IF: $1: 500$ \\
\hline Synaptophysin & $\begin{array}{l}\text { rat retinal synaptosomes } \\
\text { antigen }(38 \mathrm{kD})\end{array}$ & $\begin{array}{l}\text { Sigma, St. Louis, MO, mouse, monoclonal, S5768, } \\
\text { RRID: AB_477523 }\end{array}$ & IF: $1: 500$ \\
\hline
\end{tabular}

Research Resource Identifiers (RRID) are also indicated.

$4 \%$ normal donkey serum (NDS), $2 \%$ bovine serum albu$\min (\mathrm{BSA})$, and $0.1 \%$ Triton $\mathrm{X}-100$ for 1 hour at room temperature. Sections were then incubated in primary antibody solution containing 1:3,000 rabbit anti-FG (Biotium) and 1:2,500 mouse anti-parvalbumin (PV; Cat. No. 235, Swant, Bellinzona, Switzerland), 1:2,500 mouse anti-calbindin (CB)-28kD (Cat. No. 300; Swant), 1:2,500 mouse anti-calretinin (Cat. No. 6B3; Swant); 1:500 goat anti-choline acetyltransferase (ChAT; Cat. No. AB144P, Chemicon, Temecula, CA), 1:1,000 mouse anti-GAD-67; Cat. No. MAB5406, Chemicon), or 1:1,500 mouse antisynaptophysin (clone SVP-38, Cat. No. S5768, SigmaAldrich, St Louis, MO) IgG diluted in TBS containing $2 \%$ NDS, $2 \%$ BSA, and $0.2 \%$ Triton X-100 for 48 hours at $4{ }^{\circ} \mathrm{C}$. For further details see below and Table 2. Sections were rinsed three times in TBS and incubated in 1:200 dilution of donkey antimouse conjugated Alexa-488 IgG (Jackson ImmunoResearch, West Grove, PA) or 1:200 dilution of donkey antigoat conjugated Cy5 IgG (Cat. No. 705-175-003, Jackson ImmunoResearch) in TBS. Sections were then briefly rinsed in $0.01 \mathrm{M}$ PBS and mounted on chrome-alum gelatin-coated slides, air-dried, dehydrated in graded ethanol, and coverslipped with DPX mounting medium (Sigma-Aldrich).

\section{Antibody characterization}

A number of characterized antisera were used in these studies (Table 2) (Olucha-Bordonau et al., 2012). The specificity of the FG antibody was verified by the presence or absence of labeling in rats injected or not injected with FG, respectively.

The monoclonal PV antibody was produced by hybridization of mouse myeloma cells with spleen cells from mice immunized with PV purified from carp muscles (Celio et al., 1988). It recognizes a single $12 \mathrm{kD}$ protein (pl 4.9) on a $2 \mathrm{D}$ immunoblot of rat cerebellar tissue, values identical to those expected for purified PV (Celio et al., 1988). Furthermore, staining was abolished in the brain of PV-knockout mice (Schwaller et al., 2004).

The monoclonal CB-28kD antibody was produced by hybridization of mouse myeloma cells with spleen cells from mice immunized with $\mathrm{CB}-28 \mathrm{kD}$ purified from chicken gut (Celio et al., 1990). Staining was abolished in the brain of CB-28kD-knockout mice (Airaksinen et al., 1997).

The antibody against calretinin (Swant) was produced in mice by immunization with recombinant human calretinin-22k (Zimmermann and Schwaller, 2002). Staining was abolished in the brain of calretininknockout mice (Schurmans et al., 1997).

The goat polyclonal antiserum against ChAT has been shown to stain a single band of 68-70 kD molecular weight by western blot analysis of mouse brain lysate (manufacturer's technical data) and its antigen specificity has been determined by preadsorption with purified protein (Rico and Cavada, 1998).

The mouse antibody against GAD-67 has been shown to react with the $67 \mathrm{kD}$ isoform of $\mathrm{GAD}$ from rat, mouse, and human (manufacturer's technical data). It displayed no detectable crossreactivity with GAD-65 on western blots of rat brain lysate compared to antibody AB1511 (Chemicon) that reacts with GAD-65 and GAD67 (Biancardi et al., 2010).

The monoclonal antibody against synaptophysin was raised using rat retina synaptosomes and it stains synaptophysin in neurons (Booettger et al., 2003).

\section{Immunofluorescence analyses}

FG immunostaining was imaged using a Nikon Eclipse E600 microscope with a DMX2000 digital camera 
(Nikon, Tokyo, Japan) and maps were constructed using a camera lucida tube attached to a Zeiss Axioskop microscope (Zeiss, Munich, Germany). Drawings were made with $20 \times$ and $40 \times$ magnifications, scanned, and reduced to their final size. Confocal immunofluorescence was imaged with a laser confocal scan unit TCSSP2 equipped with argon and helio-neon laser beams attached to a Leica DMIRB inverted microscope (Leica Microsystems). Wavelengths for FG excitation were $351 \mathrm{~nm}$ and $364 \mathrm{~nm}$ and for emission 382-487 nm; $\mathrm{mR}$ excitation was $433 \mathrm{~nm}$ and for emission 560$618 \mathrm{~nm}$; Alexa488-labeled antibody excitation was $488 \mathrm{~nm}$ and for emission was 510-570 nm; Cy5labeled antibody excitation was $633 \mathrm{~nm}$ and for emission $644-719 \mathrm{~nm}$. Serial $0.5-\mu \mathrm{m}$ scans were obtained in the Z-plane and a maximal projection of up to $10 \mu \mathrm{m}$ was generated with Leica confocal software (V2.61).

\section{RESULTS}

In these experiments a series of different neural tracer injections were made into the septum, the $\mathrm{NI}$ and related anatomical areas, and the data were analyzed based on the accuracy and extent of the injections and the resultant labeling (see Table 2). Following FG injection into the $\mathrm{NI}$ of adult male rats $(n=7$; Fig. $1 \mathrm{~A}-\mathrm{E})$, dense retrograde labeling was observed in the septal area $(n=7$; Fig. 1F,G). Control cases for these injections were used to confirm that FG-positive neurons in septal areas were specifically observed in brains with injection sites including the $\mathrm{NI}(n=2$; Fig. 1C,D). Conversely, anterograde labeling of dense fiber plexuses in the $\mathrm{NI}$ was observed following $\mathrm{mR}$ injections into the septal area $(n=12$; Fig. 2A,B). Information regarding tracer injection sites, areas of tracer diffusion, and the analysis completed are summarized in Table 1. In some rats, we combined retrograde tracer injections in the hippocampus (Fig. 2C) with anterograde tracer injections in the MS/DB (Fig. 2E).

\section{Retrograde tracer-positive neurons in septum following FG injections into the $\mathrm{NI}$}

$F G$ injections in the $\mathrm{NI}$ included four cases $(\mathrm{CCH} 5$, $\mathrm{CCH} 11, \mathrm{RS} 31$, and RS29) in which the injection site was centered in the $\mathrm{NI}$ with little or not diffusion to surrounding areas (Fig. 1A-D). In one such case (RS31), the injection site only covered a small area of the NIc (Fig. 1E) and resulted in rare but consistent cellular labeling in the medial septal division. Also, in three cases (CCH12, RS26, RS27) the diffusion area also spread to the pontine reticular formation. Finally, in two cases (CCH8 and $\mathrm{CCH} 10)$ the injections were centered in the reticular formation without diffusion to
NI. No retrograde labeling was seen in the septal area of these cases. The pattern of retrograde labeling in the septal area was similar in all cases in which the injection site included the NI. Representative camera lucida drawings of case $\mathrm{CCH} 5$ are illustrated (Fig. 3). Most FG-positive neurons observed were concentrated in the MS/DB, although dispersed neurons were observed in the lateral septal area. We analyzed five rostrocaudal levels of the septum in the coronal plane (250 $\mu \mathrm{m}$ apart; Fig. 3A-E).

Level 1 ( pregma $+1.80 \mathrm{~mm}$ ) is the most anterior and corresponds to a coronal plane at which the MS/ DB of the right and left hemispheres is separated by the ependyma (Fig. 3A). At this level, a column of retrogradely labeled neurons in the MS and dispersed neurons in the LSI were observed, but no retrograde labeling was observed in the LSD. Level 2 ( bregma $+1.28 \mathrm{~mm}$ ) corresponds to the coronal plane where the MS/DB consists of two clearly defined segments"vertical" containing MS and VDB and "horizontal" containing the HDB (Fig. 3B). At this level, some dispersed retrogradely labeled neurons appeared in the medial aspects of the lateral septum corresponding to the LSI, but the majority of retrograde labeling was concentrated in the MS/DB. Within the MS and the VDB, retrogradely labeled neurons were present in a strip in a middle zone of the MS (Fig. 3B). Level 3 ( bregma $+0.60 \mathrm{~mm}$ ) is where the fiber tracts of the fornix (f) become evident (Figs. 3C, 4A). Retrograde labeling occurred between the bundles of the fornix, which we interpret as the rostral extension of the septofimbrial (SFi) nucleus (Fig. 4C). At this point, little or no retrograde labeling was observed in the LS, whereas the MS/DB displayed dispersed labeling in the $M S$ and $V D B$ and concentrated in a band in the HDB (Figs. 3C, 4D). A region with no labeling appeared between the superficial surface of the brain and FG-positive cells cluster in the HDB (arrows in Fig. 3C). Level 4 ( $\sim$ bregma $-0.20 \mathrm{~mm}$ ) is where the SFi is clearly distinguished (Fig. 3D). A cluster of labeled neurons were present in the ventral division of the LSV. At this level, a few retrogradely labeled neurons were observed between the fornix bundles of the SFi nucleus. Some other labeled neurons also occurred in the central area of the septum occupied by the TS (Fig. 4E). Notably, a significant number of labeled neurons were observed in the HDB. There was a clear difference between the dense labeling in the HDB compared to the more dispersed labeling in the SFI and TS. Also, some neurons were observed in the lateral preoptic nucleus (LPO) in the hypothalamus that seemed to be in continuity with the septal retrograde labeling. Few retrogradely labeled neurons 
A

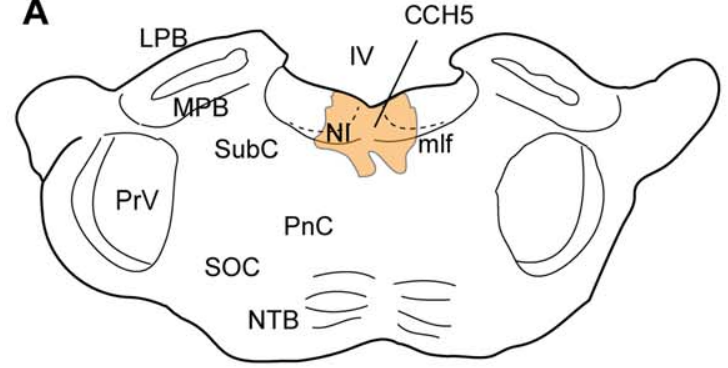

Bregma -9.48

C

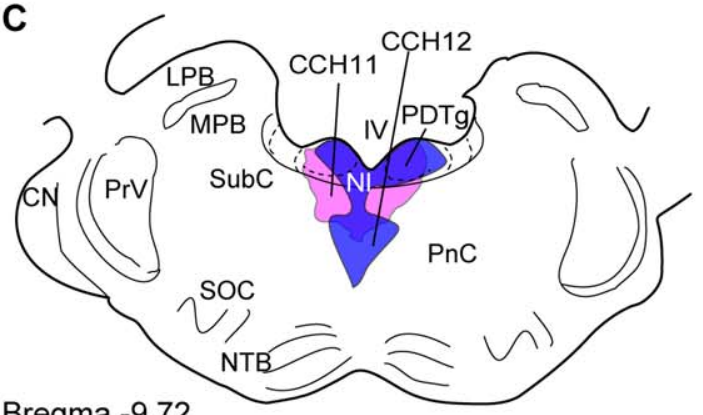

Bregma -9.72
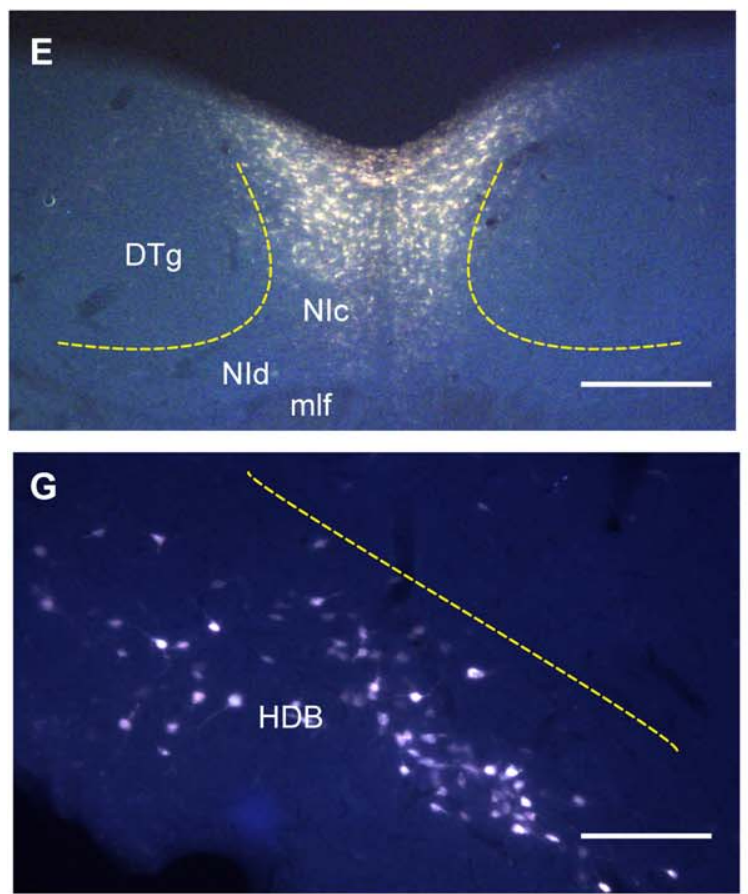

B
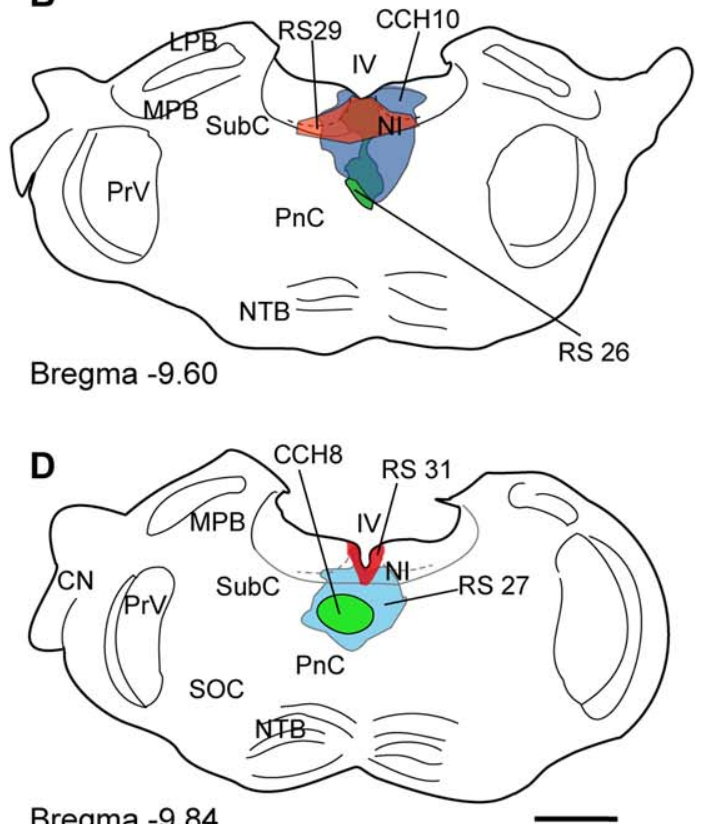

Bregma -9.84

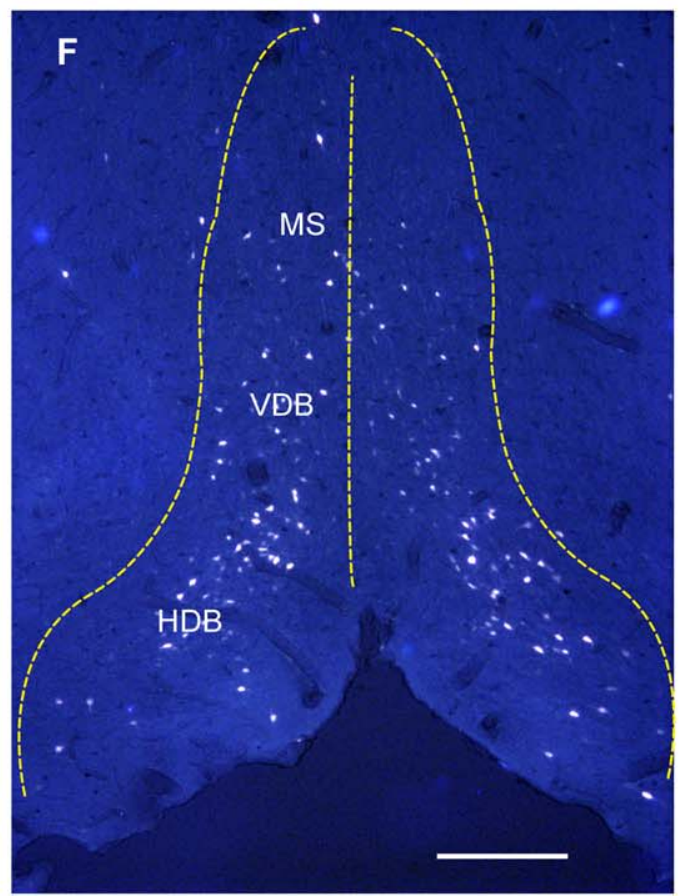

Figure 1. Fluorogold (FG) injection sites in nucleus incertus ( $\mathrm{NI})$ and surrounding regions. Camera lucida drawings illustrating the injection sites for the retrograde tracer, FG, in the NI. FG injections were centered in the $\mathrm{NI}$ in cases CCH5 (A), RS29 (B), CCH11 (C), and RS31 (D). FG injections in $\mathrm{NI}$ and adjacent reticular formation were observed in cases RS26 (B), CCH12 (C), and RS27 (D). Injection sites outside the $\mathrm{NI}$, in the reticular formation, were used as controls, cases $\mathrm{CCH} 10$ (B) and $\mathrm{CCH} 8$ (D). Location of a very restricted injection, case RS31 (E). Retrograde labeling in the MSDB at rostral level, case CCH5 (F). Retrograde labeling in a cluster of HDB at the caudal level 4, $\mathrm{CCH} 5$ case (G). For abbreviations, see list. Scale bars $=1 \mathrm{~mm}$ for A-D; $200 \mu \mathrm{m}$ for E,F; $100 \mu \mathrm{m}$ for G. [Color figure can be viewed in the online issue, which is available at wileyonlinelibrary.com.]

were observed in the LSD and bed nucleus of the stria terminalis (ST; Fig. 3D). Finally, Level 5 ( bregma $-0.70 \mathrm{~mm}$ ) contains caudal levels of HDB (Fig. 3E). At this level, dispersed retrogradely labeled neurons were observed in the lateral caudal levels of the HDB, with little to no labeling between the bundles of the fornix and hippocampal commissure (Fig. 3E). 


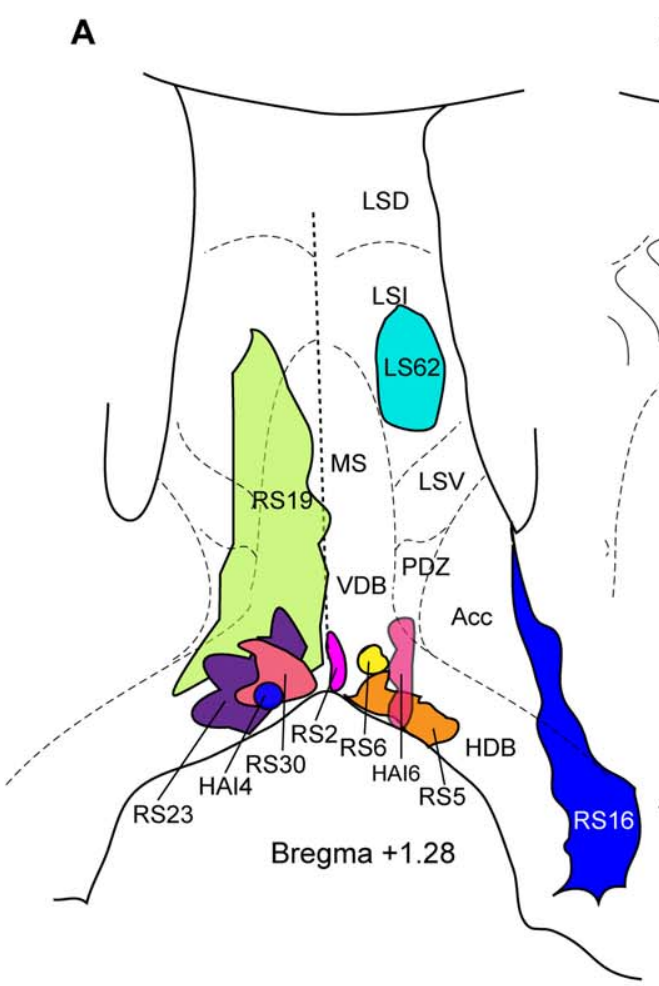

B
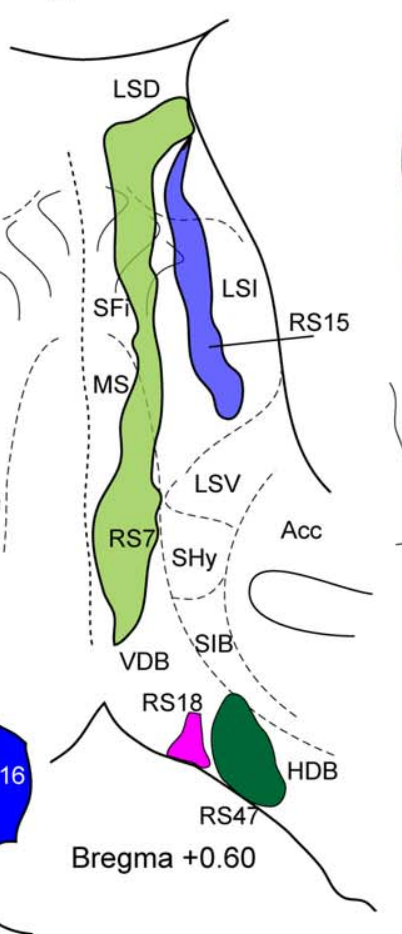

C
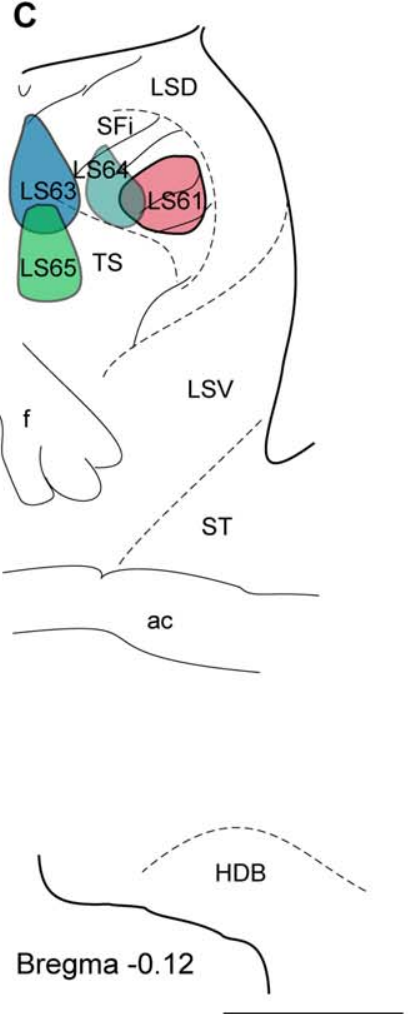
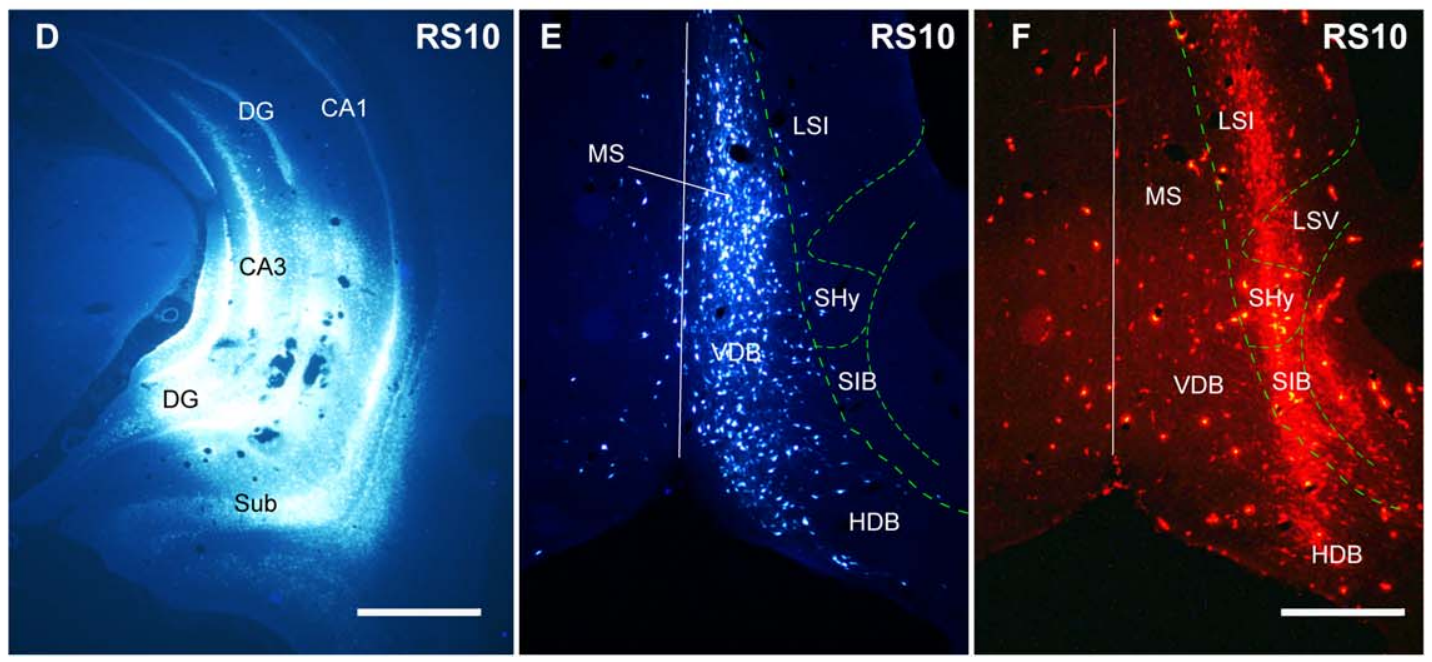

Figure 2. Miniruby (mR) and BDA injection sites in the septal area and Fluorogold (FG) injection site in hippocampus. Camera lucida drawings illustrating all the injection sites for the anterograde tracers in the septal area. Analysis was based on seven injections centered in the HDB and MS/VDB (cases RS2, RS5, RS6, RS18, RS23 RS30, mR and RS47, BDA); five injections that included parts of MS and LS (cases RS7, RS16 and RS19, mR; A,B), and two injections (RS15, mR and LS62, BDA) restricted to lateral septum (A,B) and four injections into the posterior septum (C), which included the triangular septum (LS63 and LS65, BDA) and the septofimbrial nucleus (LS61 and LS64, $\mathrm{BDA}$ ). In case RS10, mR, an FG injection into the hippocampus (D), which resulted in retrograde labeling in the MS/VDB (see E), was combined with an $\mathrm{mR}$ injection in LS (F). The injection site of case RS10 is not drawn in A-D. For abbreviations, see list. Scale bars $=1 \mathrm{~mm}$ in A-C; $500 \mu \mathrm{m}$ in D-F. [Color figure can be viewed in the online issue, which is available at wileyonlinelibrary.com.]

\section{Characterization of septal neurons projecting to $\mathrm{NI}$}

Septal neurons projecting to the NI were further characterized using immunofluorescent labeling for specific neuronal markers. Notably, no colocalization of FG with ChAT was observed in any case and in some regions, these markers appeared to differentiate septal divisions (Fig. 5AI). In the MS and VDB, FG-labeled neurons were detected close to the midline (Fig. 5A,C), whereas ChAT-positive neurons were generally observed in lateral aspects (Fig. 5B,C). 


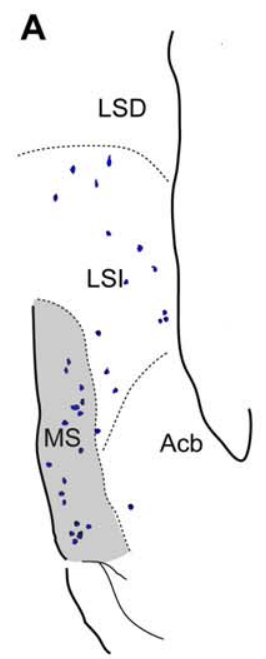

Level 1

Bregma +1.8
B

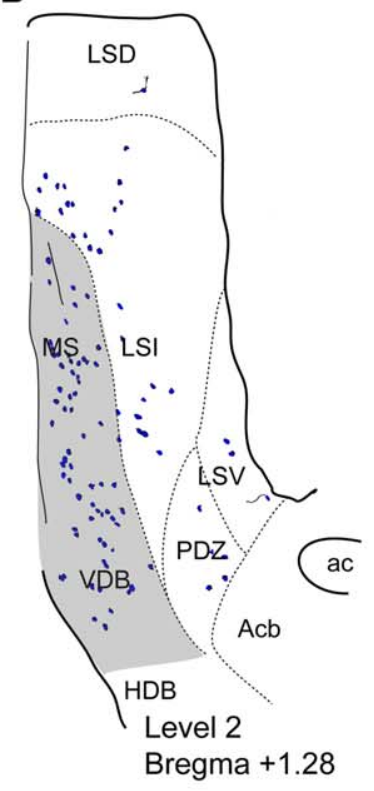

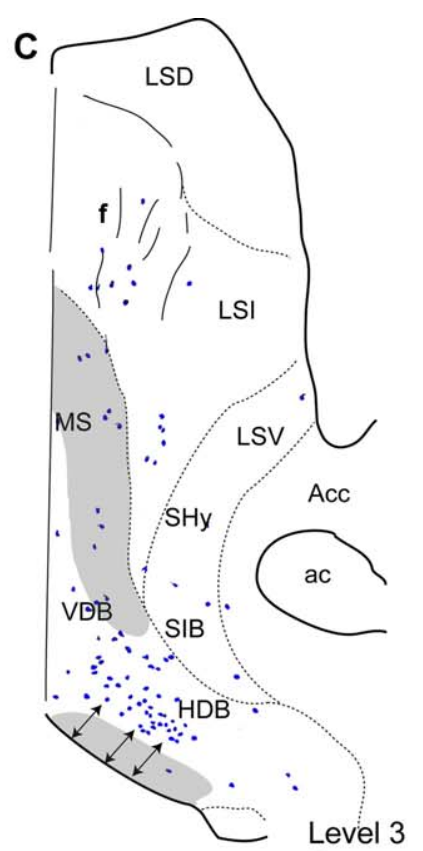

Bregma +0.60

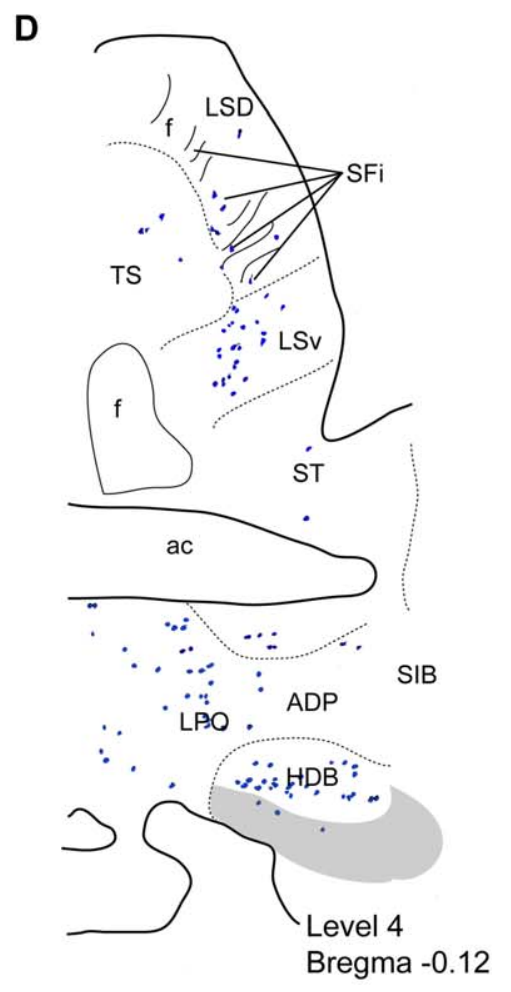

E

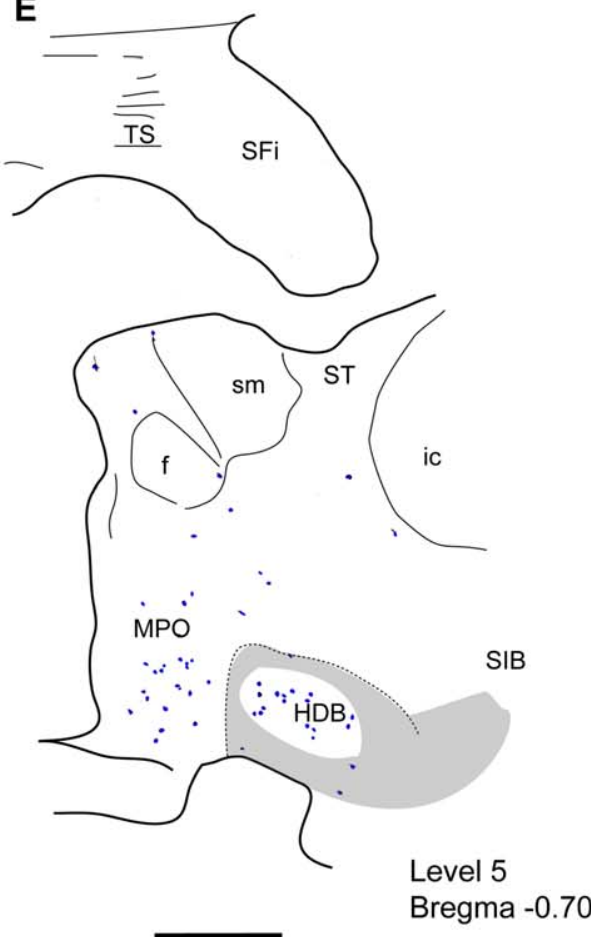

Figure 3. Distribution of FG retrograde labeling in the septal area (case CCH5). Camera lucida drawings illustrating the different levels of the septum analyzed. As an anatomical reference, the location of ChAT-positive neurons is illustrated by the gray-shaded area. (A) Level 1 ( bregma $+1.8 \mathrm{~mm}$ ): the two septal areas (medial and lateral) appear physically separated. Most FG-positive neurons were detected in MS and VDB with some dispersed labeling in LSI. (B) Level 2 ( bregma $+1.28 \mathrm{~mm})$ : continuity exists between HDB and VDB. FG-positive neurons were concentrated in the MS/DB and sparse in LSI. (C) Level 3 ( bregma $+0.60 \mathrm{~mm}$ ): a clear division is observed between HDB and VDB and the fornix becomes evident in the dorsal tip of the MS. FG-positive neurons were concentrated in the HDB. (D) Level 4 ( bregma $-0.12 \mathrm{~mm}$ ): the anterior commissure is interposed between the HDB and the posterior septal area, composed of the triangular septal area (nucleus) (TS), the septofimbrial nucleus (SFi), and LSD. FG-positive cells were observed in HDB and LSv and dispersed neurons were observed within the SFi. (E) Level 5 ( bregma $-0.70 \mathrm{~mm}$ ): most caudally, the posterior septum is composed of the triangular septal and the septofimbrial nuclei and only HDB is visible. The distribution of FG-positive neurons was generally sparse, but neurons were concentrated in the HDB. For abbreviations, see list. Scale bar $=500 \mu \mathrm{m}$. [Color figure can be viewed in the online issue, which is available at wileyonlinelibrary.com.] 

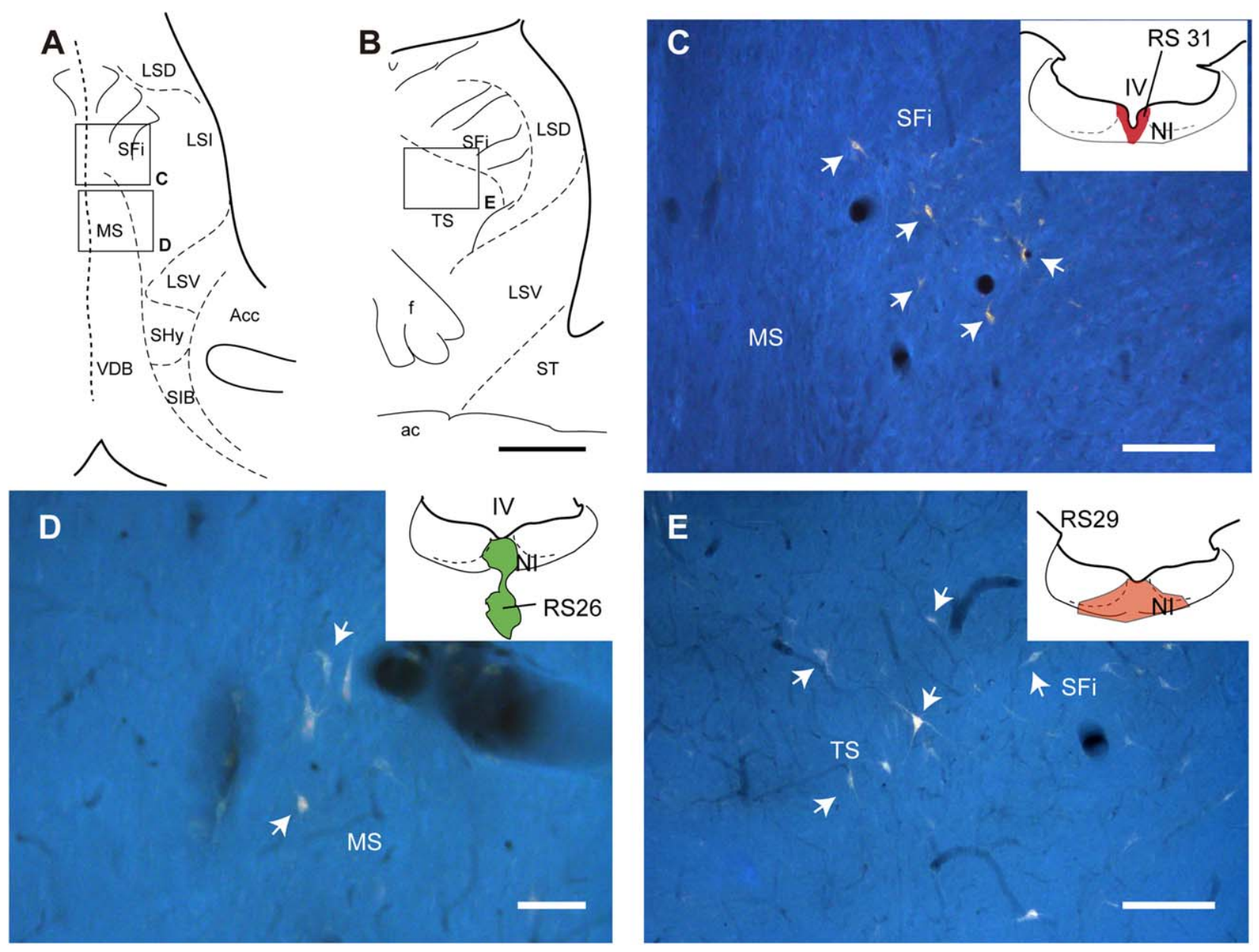

Figure 4. Retrograde labeling in the septal area after FG injections centered in the NI. (A) Diagram illustrating the septal level 3 containing two areas with retrograde labeling illustrated in images in $C$ and $D$ which corresponds to level bregma -0.6 , as it appears in Fig. 3C. (B) Diagram illustrating the septal level 4, corresponding to bregma -0.12 as it appears in Fig. 3D, containing the area with retrograde labeling illustrated in image E. (C) Retrograde labeling in the SFi nucleus after FG injection in the NI in case RS30 (inset). Despite the small injection consistent retrograde labeling was seen in the SFi nucleus (arrow). (D) Retrograde labeling in the MS nucleus after a large FG injection into the $\mathrm{NI}$ with some spread to the ventrally located reticular formation including the raphe pontis nucleus in case RS26 (inset). Some retrograde labeling (arrow) was detected in the MS after large injections. (E) Retrograde labeling in the TS and SFi nuclei of the posterior septum after FG injection in the NI in case RS29 (inset). Some dispersed retrograde labeling (arrow) occurred in both nuclei. Scale bars $=250 \mu \mathrm{m}$ in A,B; $100 \mu \mathrm{m}$ in C,E; $50 \mu \mathrm{m}$ in D. [Color figure can be viewed in the online issue, which is available at wileyonlinelibrary.com.]

Even in areas where these two neuronal populations "overlapped," no colocalization of the markers was observed (see higher-magnification images; Fig. 5D-F). In addition, FG-labeled neurons were observed in a long strip within the HDB (Fig. 5G,I), while ChAT-positive neurons were concentrated in a superficial band (Fig. $5 \mathrm{H}, \mathrm{I})$. Interestingly, a band of unlabeled neurons/tissue was present between the ChAT and FG-positive neurons (Fig. 5l).

In contrast to the lack of colocalization of FG in cholinergic neurons, we observed some colocalization of FG and calcium-binding proteins in neurons in the HDB. CB$28 \mathrm{k}$-positive cells were not abundant within the MS, but we observed clear colocalization with FG (Fig. 6A-C). In contrast, only a few of the more abundant PV-positive neurons contained FG (Fig. 6D-F,G-I). Similarly, we observed only a few neurons containing FG and GAD-67 in these same areas within the HDB (Fig. 6J-L,M-O).

Staining for $F G$ and calretinin (CR) in the MS/DB revealed a large number of CR-positive retrogradely labeled neurons in both MS (Fig. 7A-C) and HDB (Fig. 7D-F). In contrast, in the triangular septal and septofimbrial nuclei of the posterior septum, areas containing a considerable number of CR-positive neurons, little FG staining was observed. Moreover, the few FG-positive neurons observed in these areas did not contain CR staining (Fig. 7G-I). These observations suggest the existence of specific CR-containing projections from the MS to the NI.

There was some variability in the number of retrogradely labeled septal neurons after FG injections in the $\mathrm{NI}$. Therefore, a reliable quantitative assessment of the 

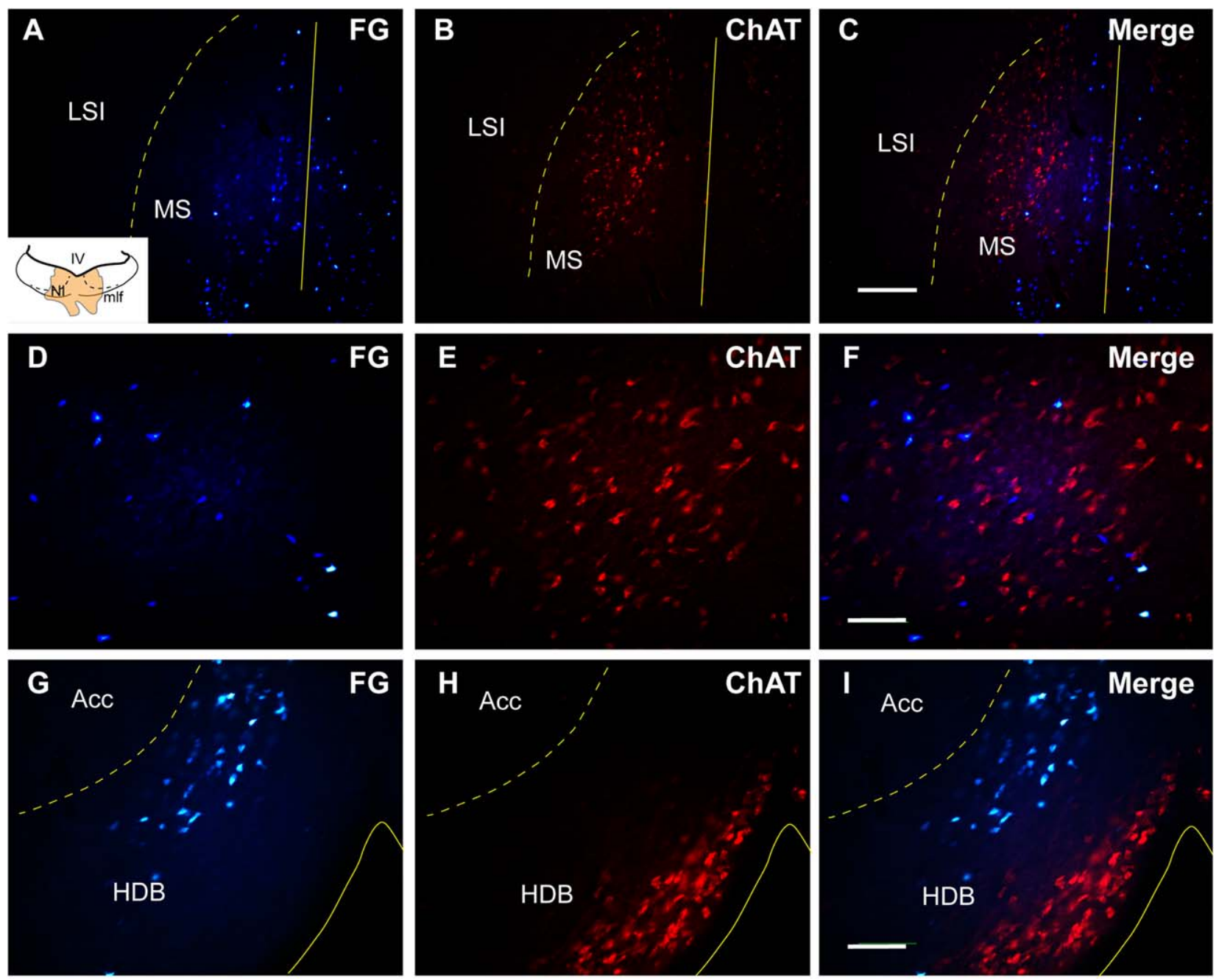

Figure 5. ChAT-positive neurons in MS and HDB do not send descending projections to $\mathrm{NI}$ (case CCH5). Double immunofluorescence staining for ChAT and FG in MS and HDB in case CCH5. A differential distribution of the population of cholinergic and NI-projecting neurons was observed. (A-C). In the MS, FG-positive neurons were located medially (A), whereas ChAT positive neurons were detected typically in the outer part of the MS (B), with a small degree of overlap between the two cell groups at the intersection between the major areas (C). (D-F) High-magnification images of the overlapping areas reveal the absence of any colocalization of the fluorescent signals. (G-I) In the HDB, FG-positive neurons occupied an inner or deeper layer, adjacent to the nucleus accumbens (Acc) (G), whereas ChATpositive neurons were located more superficially $(\mathrm{H})$ and no overlap was observed between the areas occupied by the two markers (I). For abbreviations, see list. Scale bars $=50 \mu \mathrm{m}$. [Color figure can be viewed in the online issue, which is available at wileyonlinelibrary.com.]

proportion of labeled neurons that express each of the septal neuron markers was not possible. However, we made a semiquantitative evaluation of the percentage of FG-labeled neurons that express each of the markers. As mentioned, none of the FG-labeled cells expressed ChAT. Some $2 \%$ of the FG-labeled cells expressed PV, while a slightly higher percentage of FG-positive cells contained CB-28kD. In contrast, more than 50\% of the FG-positive MS/DB neurons contained CR. Finally, only a low proportion of FG-positive neurons expressed GAD-67 immunoreactivity, which, despite possible technical issues regarding the detection limits of the different markers, left a significant proportion of FG-positive MS/DB neu- rons uncategorized. This finding also suggests that a substantial proportion of $\mathrm{NI}$ projecting CR-positive neurons are not GAD-67-positive (i.e., not GABAergic).

\section{Anterograde fibers in the $\mathrm{NI}$ following $\mathrm{mR}$ injection in the MS}

In studies to confirm that neurons of the MS/DB send projections to the $\mathrm{NI}$, the anterograde tracer, $\mathrm{mR}$, was injected into different septal areas (Figs. 2A,B,F, 8G, 9A,E, 10A,E). In eight cases (HAl4, HAl 6, RS5, RS6, RS18, RS23, RS30, and RS47), the injection was restricted to an area of $150-250 \mu \mathrm{m}$ within the HDB 

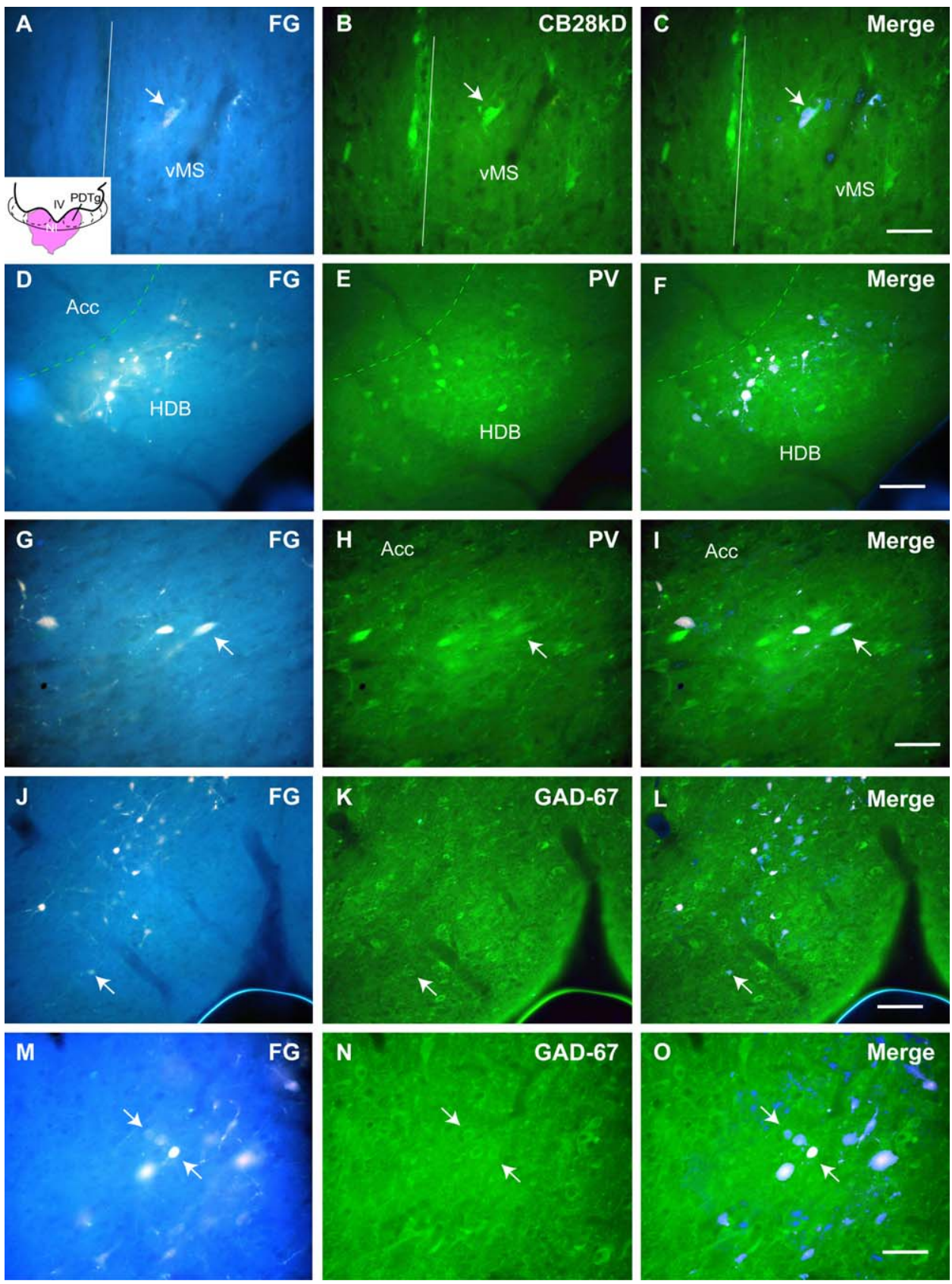

Figure 6. Characterization of the neurochemical nature of septal neurons projecting to NI. Double immunofluorescence staining of FGlabeled neurons and the calcium-binding proteins-calbindin (CB-28kD) and parvalbumin (PV)-and GAD-67 in case CCH11. (A-C) Some FG-positive neurons were positive for CB-28kD (colocalization indicated by arrow). (D-I) Although FG-positive and PV-positive neurons occupy the same area within the HDB, no significant colocalization was observed (D-F), although sparse double-labeled neurons were identified (G-I, colocalization indicated by arrow). Some FG-positive neurons (J) containing GAD-67 were observed (K-L, colocalization indicated by arrow). For abbreviations, see list. Scale bars $=50 \mu \mathrm{m}$ in A-C,G-I,M-O; $100 \mu \mathrm{m}$ in D-F,J-L.

and another case (RS2) had a restricted injection in the VDB (Fig. 2A,B). In cases LS62 and RS15, the injection site was located in the LSI (Fig. 2A). In cases LS61 and LS64, the injection site was centered in the TS and in the cases LS63 and LS65 the injection site targeted the septofimbrial nucleus (Fig. 2C). Finally, in four cases (RS7, RS10, RS16, RS19) the injection occupied parts of the
MS and LS (Fig. 2A,B). However, no anterograde labeling was observed within the $\mathrm{NI}$ when the injection site did not occupy either HDB or posterior septum. Following large injections such as cases RS7 and RS19 centered in the MS, VDB, and LS, scarce anterograde labeling was seen in NI. Although not abundant, anterogradely labeled fibers from septal injections were consistently present in 

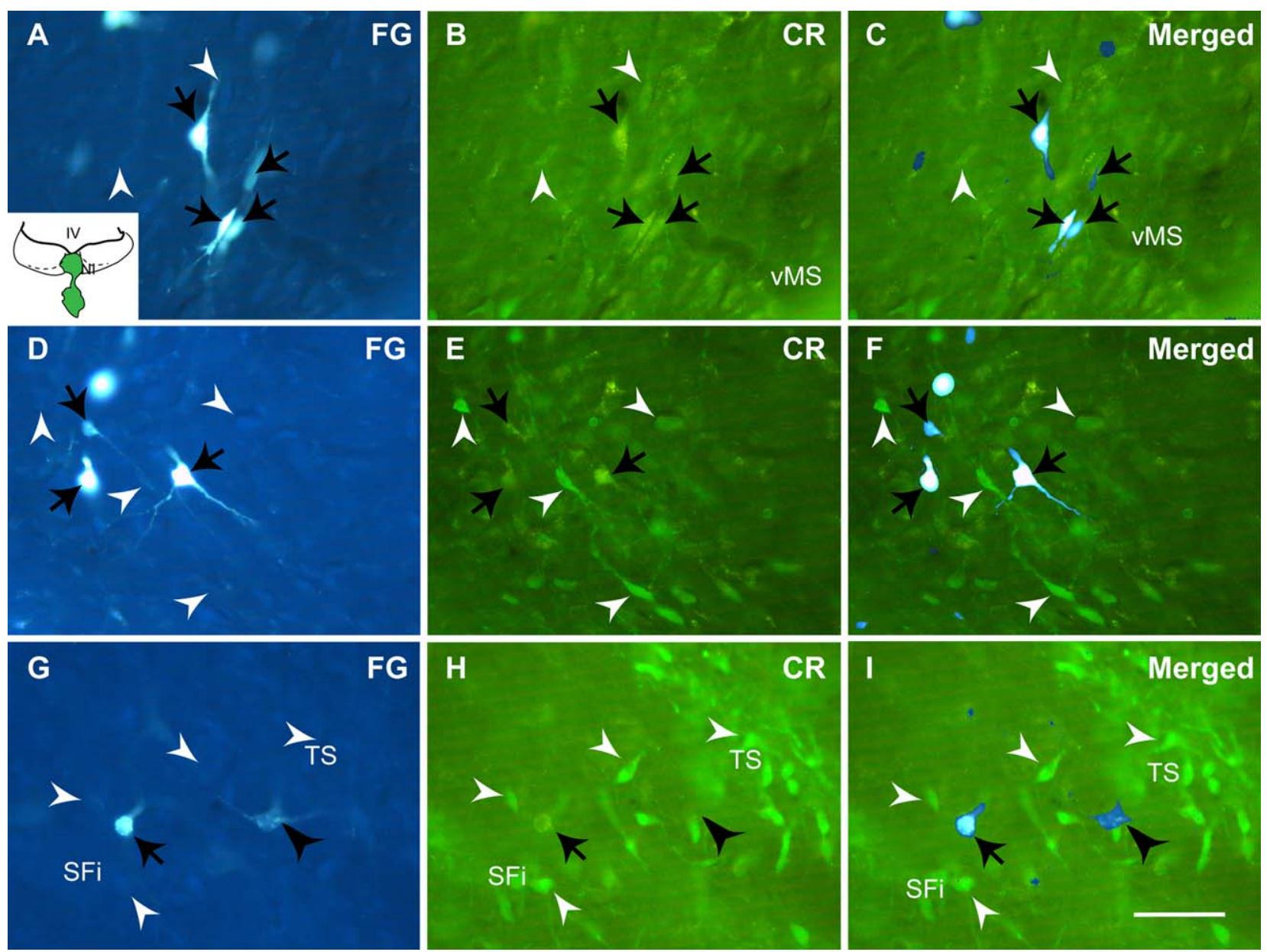

Figure 7. A majority of septal neurons projecting to $\mathrm{NI}$ contain calretinin. Double immunofluorescence staining of FG-labeled neurons and calretinin-positive neurons in the septum of case RS26. (A-C) In this case, with an FG injection within the $\mathrm{NI}$ and the adjacent pontine reticular formation, a majority of FG-positive neurons were observed in the VDB and the HDB (D-F) and were positive for calretinin (black arrows), while other calretinin-positive neurons were not FG-labeled (white arrowheads). (G-I) FG-labeled neurons in the triangular septal nucleus were calretinin-positive (black arrow), also another FG-positive is CR-negative (black arrowhead) and others were calretininnegative (white arrowheads). For abbreviations, see list. Scale bar $=50 \mu \mathrm{m}$.

the $\mathrm{NI}$ after all injections that occupied either the HDB, $\mathrm{TS}$, or SFi; while trace or no anterograde labeling was detected when injections affected the MS, VDB or any of the LS nuclei (Fig. 9E-H, case LS62).

In all cases containing anterograde labeling in the NI, descending fibers from the injection site coursed primarily through the LPO area and dispersed through the perifornical area. More caudally, labeled fibers coursed through the dorsal and ventral premammillary nuclei and the lateral supramammillary nucleus. Some labeled fibers were also observed in the posterior hypothalamic nucleus. In the midbrain, some labeled fibers were dispersed within the ventral tegmental area and median and paramedian raphe nuclei. Finally, labeled fibers coursed via the pontine raphe nucleus to reach the NI located more dorsally. Overall, only a moderate proportion of the descending fibers reached the NI.
In the analysis of the distribution of the anterograde labeling within the $\mathrm{NI}$, we identified three coronal levels. In the rostral most level ( bregma $-9.60 \mathrm{~mm}$ ) (Fig. $8 \mathrm{~A}$ ), the $\mathrm{NI}$ continued ventrally with the pontine raphe nucleus. At the second level ( bregma $-9.72 \mathrm{~mm}$ ) (Fig. 8B) the sulcus of the fourth ventricle (IV) is already present, but there is still a ventral communication with the pontine raphe nucleus. Finally, at the third level ( bregma $-9.84 \mathrm{~mm}$ ), a few labeled fibers appeared in the ipsilateral $\mathrm{NI}$ and some of them entered the dorsolateral tegmentum; also, some labeling was found in the contralateral NI. At the three levels, the medial longitudinal fascicle enclosed the NI ventrally.

When using $\mathrm{mR}$ as an anterograde tracer, the injection site was generally more restricted, and although consistent in all cases the amount of anterograde labeling was quite low. Therefore, we also used BDA, which 

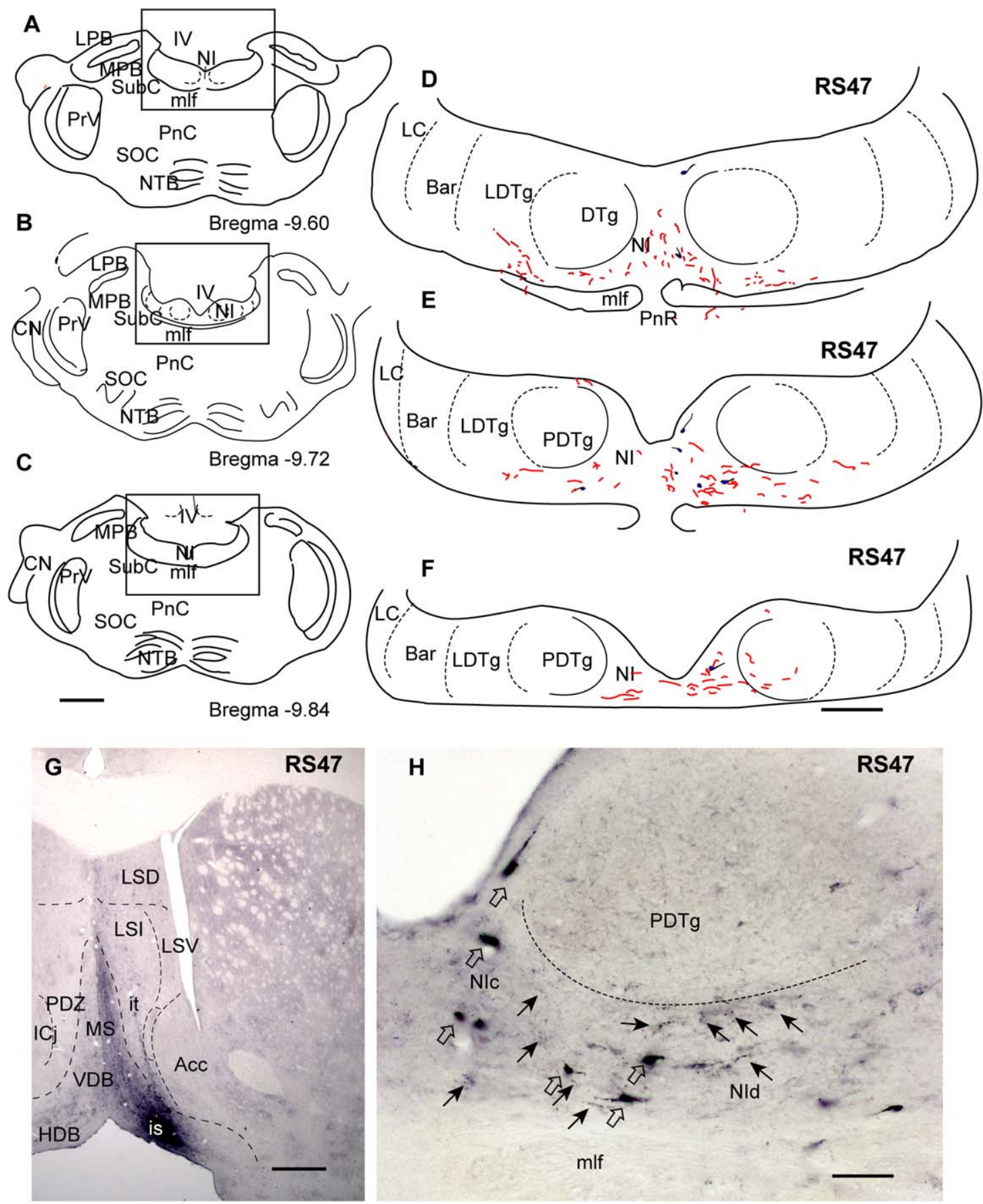

Figure 8. Anterograde labeling in $\mathrm{NI}$ after a restricted injection of BDA into the HDB (case RS47). Three coronal hindbrain levels that include parts of the $\mathrm{NI}$ were analyzed, corresponding to (A) $-9.2 \mathrm{~mm}$, (B) $-9.6 \mathrm{~mm}$ and (C) $-9.8 \mathrm{~mm}$ from bregma. (D-F) The boxed areas indicated in A-C are illustrated in camera lucida drawings for case RS47 of a BDA injection in the HDB. (G) Injection site. (H) A brightfield micrograph of the area between the NIc and NId, illustrating retrogradely labeled neurons (open arrows) and anterograde labeling (arrows). For abbreviations, see list. Scale bars $=1 \mathrm{~mm}$ in A-C; $250 \mu \mathrm{m}$ in D-F; $500 \mu \mathrm{m}$ in G; $100 \mu \mathrm{m}$ in $\mathrm{H}$. [Color figure can be viewed in the online issue, which is available at wileyonlinelibrary.com.]

provided larger injections and stronger anterograde labeling. In case RS47 with a prominent BDA injection in the HDB (Fig. 8B-H) bilateral anterograde labeling was seen at the three $\mathrm{NI}$ levels analyzed. Although retrograde labeling was also present, it was restricted to areas ipsilateral to the unilateral injection site. Restricted injections of $\mathrm{mR}$ in the HDB produced a low level of anterograde labeling, mainly observed on the ipsilateral side (Fig. 9A-D, case RS30). In contrast, anterograde labeling was not observed in the dorsal tegmental nuclei 

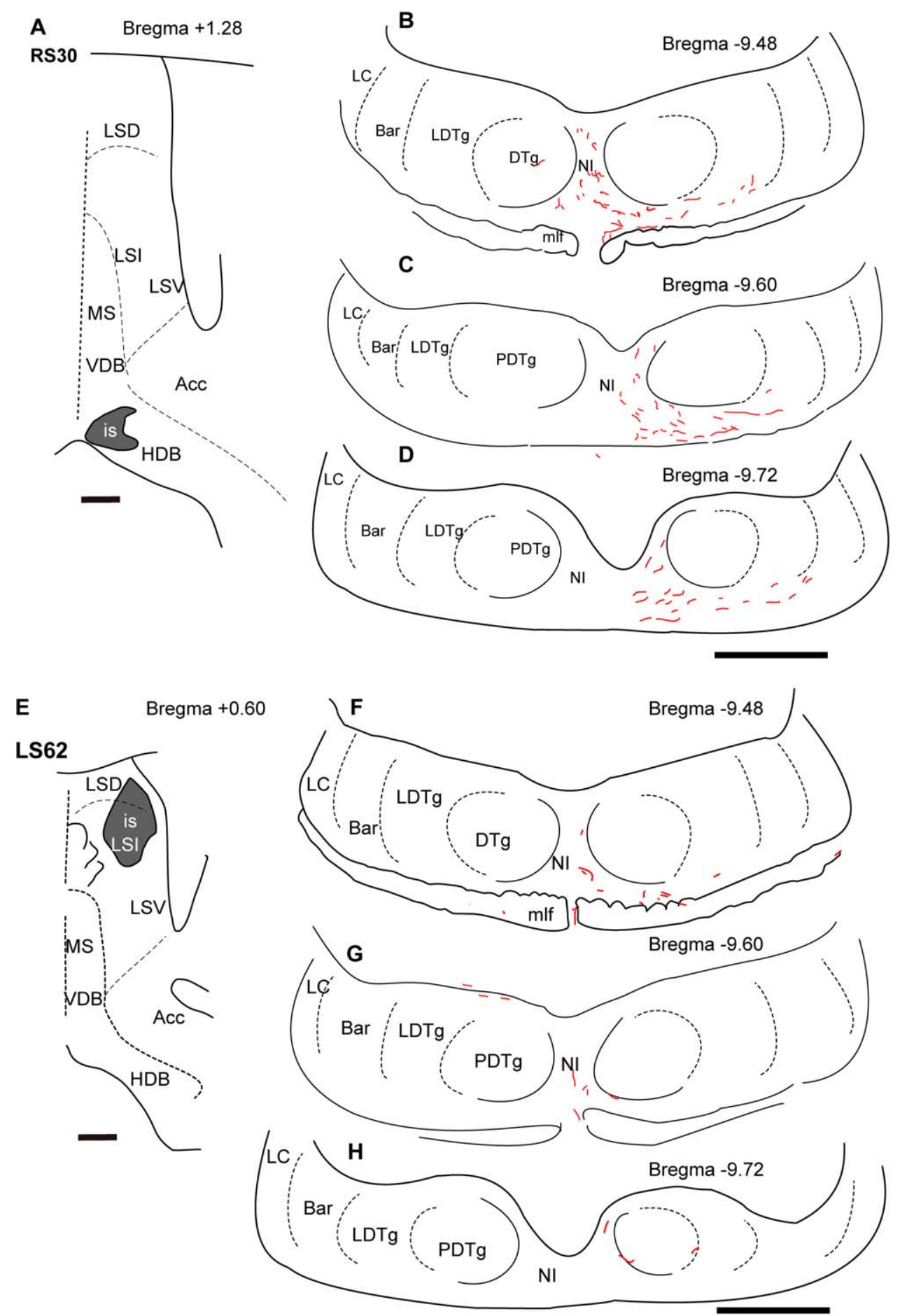

Figure 9. Anterograde labeling in $\mathrm{NI}$ after a restricted injection of $\mathrm{mR}$ into the HDB (case RS30) and an injection of BDA into the LSI (case LS62). (A) Injection site for mR in case RS30. (B-D) Anterograde labeling in the NI was mainly present ipsilaterally at the three rostrocaudal levels illustrated in Fig. 7A-C. No fibers were observed in surrounding nuclei/areas. (E) Injection site for BDA in case LS62, which was restricted to the LSI nucleus. (F-H) Anterograde labeling was only present in sparse fibers at the three rostrocaudal levels. For abbreviations, see list. Scale bars $=500 \mu \mathrm{m}$. [Color figure can be viewed in the online issue, which is available at wileyonlinelibrary.com.]

or in the more ventral reticular formation. When the injection site was located in the lateral septum (either dorsal [LSD] or intermediate [LSI]) (Fig. 9E, case LS62), only dispersed fibers were seen in the NI (Fig. 9F-H).
BDA injections into the posterior septum produced more dense anterograde labeling in the $\mathrm{NI}$ than MS/DB injections. Some labeled fibers also entered the dorsal tegmental (DTg), the posterodorsal tegmental (PDTg), 

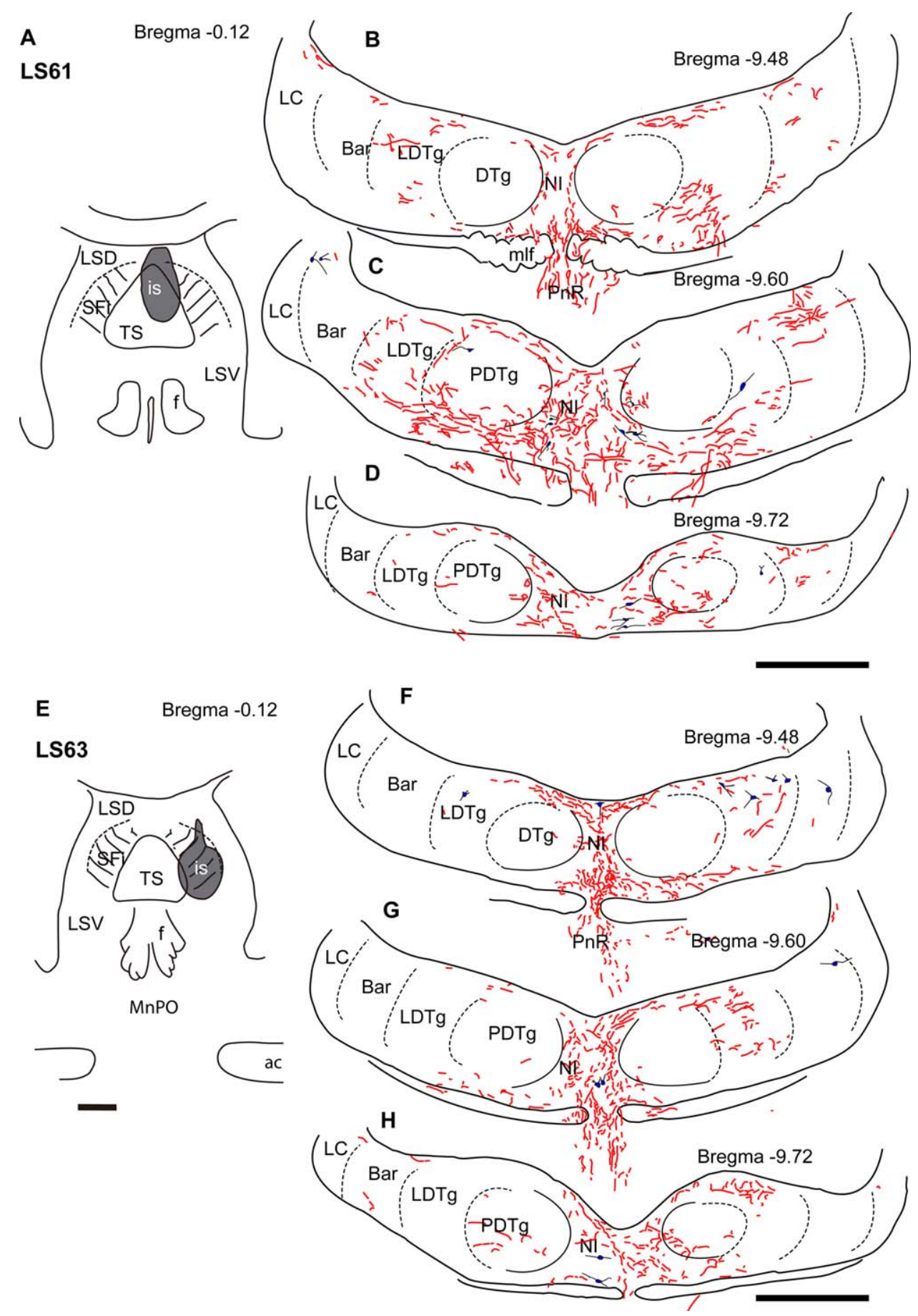

Figure 10. Anterograde labeling in NI after restricted injections of BDA into the TS (case LS61) and SFi (case LS63). (A) Injection site for BDA into TS (and the LSD) in case LS61. (B-D) Anterograde labeling in the NI transversed the pontine raphe nucleus and spread across both sides of the $\mathrm{NI}$, at the three rostrocaudal levels illustrated in Fig. 7A-C. Anterograde labeling also extended laterally into the LDTg. (E) Restricted injection site for BDA into SFi in case LS63. (F-H) Anterograde labeling was distributed along all rostrocaudal levels and on both sides of the NI. Labeled fibers were also observed in the LDTg and within the PDTg. For abbreviations, see list. Scale bars $=500 \mu \mathrm{m}$. [Color figure can be viewed in the online issue, which is available at wileyonlinelibrary.com.]

and the laterodorsal tegmental (LDTg) nuclei; although in these nuclei the density of labeled fibers was lower than in the NI. After TS injections (Figs. 2C, Fig. 10A-D, case LS61) fibers entering the $\mathrm{NI}$ formed a plexus in the pontine raphe, then spread into the two sides of the $\mathrm{NI}$ surrounding the DTg and the PDTg (Fig. 11A,B). Anterograde fibers made a plexus in the pars dissipata of the $\mathrm{NI}$ and then in the LDTg and some of these fibers were 

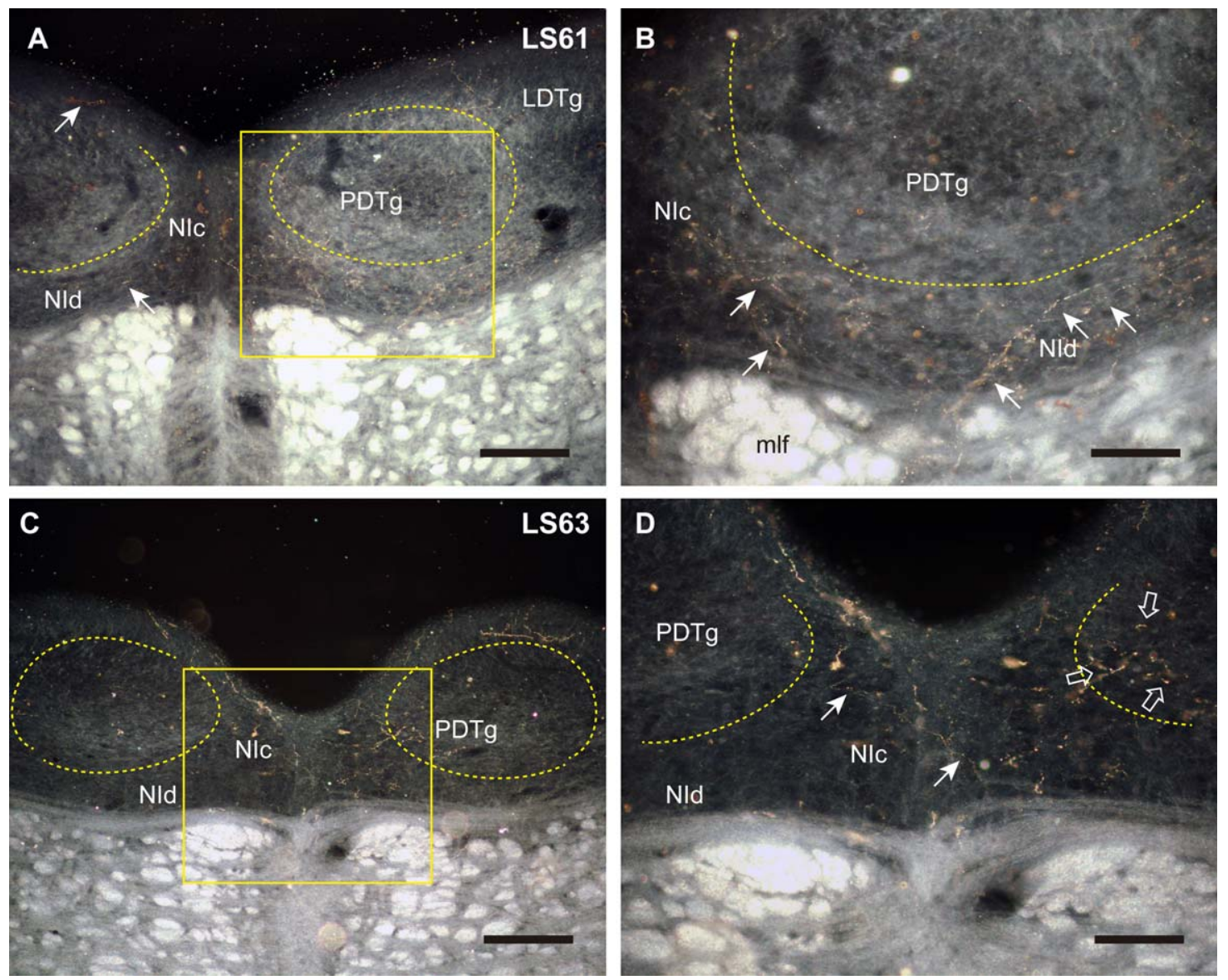

Figure 11. Illustrative example of anterograde labeling in NI observed after restricted BDA injections into the TS (case LS61) and SFi (case LS63). (A) A low-magnification image of the NI reveals the boundaries between NI and PDTg and anterogradely labeled fibers are present in the $\mathrm{NI}$ on the ipsilateral and some on the contralateral side (arrow) in case LS61. (B) A higher-magnification image (boxed area) illustrates the pattern of anterogradely labeled fibers (arrows) within the NId of case LS61. Notably there is an absence of anterograde labeling in the PDTg. (C,D) In case LS63, anterogradely labeled neurons were observed in the NI on both sides and some fibers crossed to the contralateral side from the injection (arrows). Some fibers were also observed in the PDTg (open arrows). For abbreviations, see list. Scale bars $=100 \mu \mathrm{m}$ in A,D; $40 \mu \mathrm{m}$ in B; $200 \mu \mathrm{m}$ in C. [Color figure can be viewed in the online issue, which is available at wileyonlinelibrary.com.]

detected in Barrington's nucleus. The PDTg was largely devoid of fibers (Fig. 11F-H).

Finally, injections in the SFi (Fig. 10E, case LS63) resulted in anterograde labeling in the pontine raphe nucleus with fibers ascending between the medial Iongitudinal fascicle to the $\mathrm{NI}$ to give rise to a moderate plexus in both subdivisions (NIc and NId) of both sides (Fig. 10F-H). Some fibers were also seen coursing between the two sides of the NI (Fig. 11C,D). Some labeling was also observed in the LDTg, but unlike the situation following triangular septal injections, some fibers were also seen within the PDTg nucleus (Fig. 11D).

\section{Chemical characterization of anterograde labeling in the NI}

In studies to determine whether these projections from the septal area to the $\mathrm{NI}$ made synapses in the area, we stained some anterograde tracer positive sections for synaptophysin. Using confocal microscopy, we observed $\mathrm{mR}$ anterogradely labeled fibers colocalized with synaptophysin immunoreactivity (Fig. 12A-C,D-F).

In complementary studies to confirm that MS sends GABAergic projections to the $\mathrm{NI}$, as suggested by the retrograde tracer studies (Fig. 6), we examined the colocalization of GAD67 immunoreactivity and mR anterogradely labeled fibers. As predicted, mR-labeled fibers were positive for GAD67 (Fig. 12G-L, white arrowheads). In this material, we also observed close contacts between mR-labeled fibers and GAD67positive soma in the NI (Fig. 12G-L).

\section{DISCUSSION}

In the current study we identified and characterized in detail descending projections from the MS/DB and 

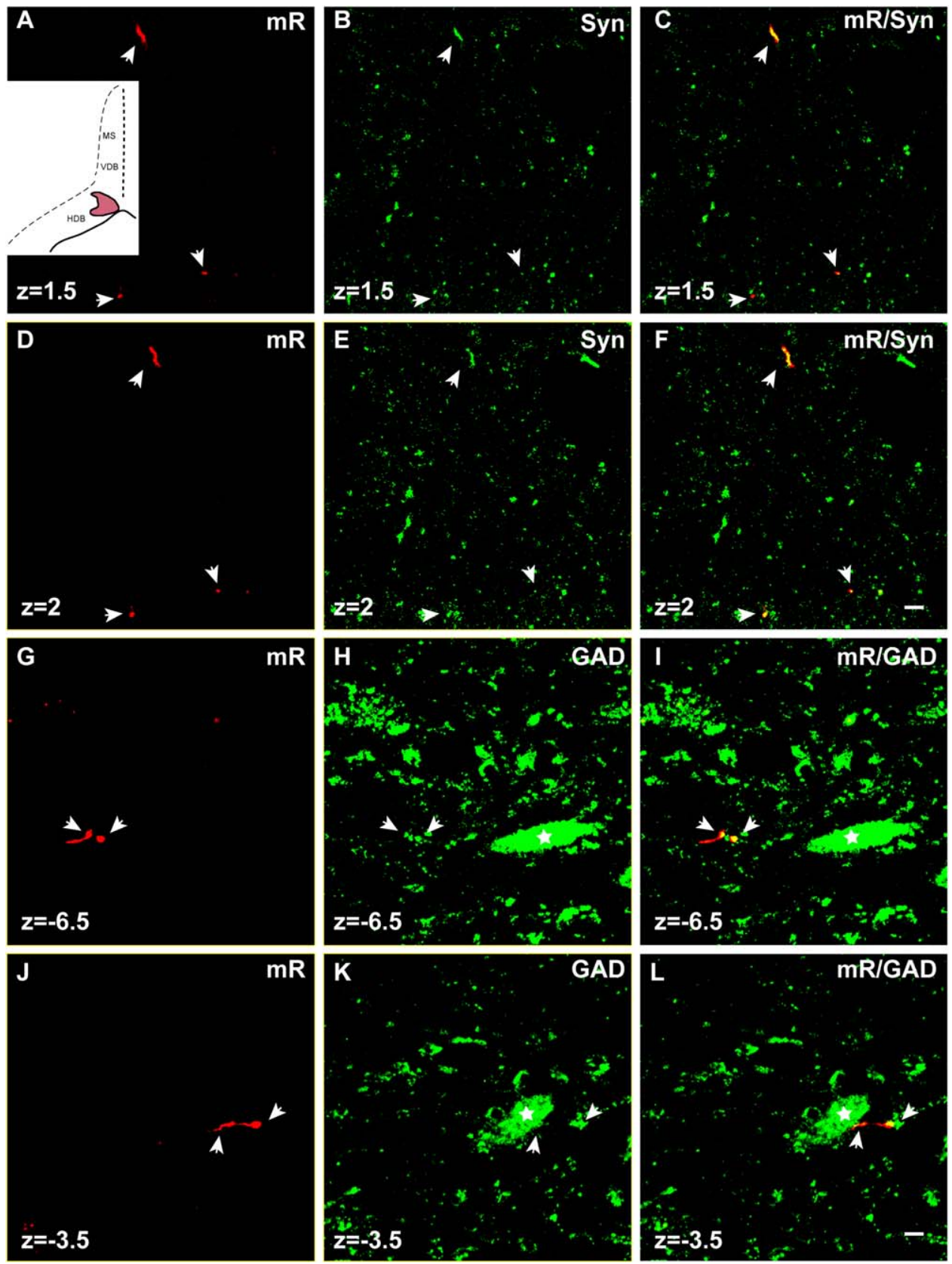

Figure 12. Colocalization of mR-labeled efferent septal fibers with synaptophysin and GAD-67 in NI. (A-F) Confocal images illustrating the colocalization of anterogradely labeled fibers with synaptophysin and GAD-67. Images of mR and synaptophysin immunostaining correspond to two single consecutive sections $0.5 \mu \mathrm{m}$ apart, illustrating putative synaptic colocalization of mR and synaptophysin (small arrows). (G-L) Colocalization of mR with GAD-67 was observed in fibers (arrows) and cells (stars). For abbreviations, see list. Scale bars $=2 \mu \mathrm{m}$. Supporting Fig. 12 is a magenta-green version.

posterior septum to the $\mathrm{NI}$ in the prepontine tegmentum of the rat. We demonstrated that some, but not all, of these projections, which, based on both anterogradeand retrograde-tract tracing, arise mainly from the HDB, and the septofimbrial and triangular septal nuclei, are GABAergic. In addition, we demonstrated that the descending septal projections make contact with GABAergic neurons in the $\mathrm{NI}$, and that most MS/DB neurons providing descending connections to the $\mathrm{NI}$ are calretinin-positive. These connections provide an anatomical basis for a feedback loop between the septal area and the NI, and a circuit between septum, NI, and hippocampus, which may function as an autoregulatory system modulating hippocampal activity during theta synchronization (Ma et al., 2013). However, the descending septal to $\mathrm{NI}$ projection is not as dense as 
its ascending counterpart and this asymmetry should be considered when addressing the "balance" within this putative functional loop. In the following, we will review our data in the light of earlier anatomical studies of septal connections, in relation to pathways thought to be involved in the regulation of hippocampal theta rhythm, and with respect to the functional implications for activity in these septal-NI-hippocampal networks.

\section{Descending projections from the MS/DB}

Descending connections from the MS/DB to the midbrain were described in early studies by Swanson and Cowan (1979), in which autoradiographic labeling in raphe nuclei and the ventral tegmental area (VTA) was detected after tritiated-amino acid injections into the MS. In other studies, retrograde tracer injections into the median and paramedian raphe revealed descending connections arising from the MS (Behzadi et al., 1990). Descending projections to histamine neurons of the posterior hypothalamus have also been documented after injection of the anterograde tracer, Phaseolus vulgaris leucoagglutinin (PHA-L), into the MS and double immunolabeling with histamine decarboxylase (Wouterlood et al., 1988). Furthermore, the supramammillary nucleus has been identified as the target of CR neurons in the MS (Borhegyi and Freund, 1998); and descending projections from the MS/DB to tegmental pontine nuclei were described after retrograde tracer injections into the LDTg (Cornwall et al., 1990). In contrast, our data indicate that the MS/DB projects to the $\mathrm{NI}$, but does not innervate the LDTg. Descending projections from the MS/DB region to pontine central gray have also been documented in mouse, following injection of adeno-associated virus (AAV) expressing green-fluorescent protein into the medial septal area (see Allen Brain Atlas, http://connectivity.brain-map.org/projection/experiment/100141597).

More recently, in in vivo electrophysiological studies of $\mathrm{NI}$ neurons in anesthetized rats, we observed both orthodromically and antidromically evoked neuronal firing of relaxin-3 and non-relaxin-3 neurons in response to electrical stimulation in the MS/DB (Ma et al., 2013), which further supports a bidirectional, functional connection between these regions. In this case, however, the orthodromic responses of $\mathrm{NI}$ neurons were more often excitatory than inhibitory, suggesting that MS stimulation resulted in glutamate and/or excitatory transmitter release in the target area. The occurrence of FG labeling in many CR-positive neurons does not exclude the possibility that a proportion of these neurons are glutamatergic.

In our material, most FG-labeled neurons were also CR-positive, but only a few were also GAD-67-positive. Although most CR-positive MS neurons projecting to the supramammillary nucleus are reportedly GABAergic, entorhinal projections to the MS/DB arise from CRpositive neurons that are characterized as aspartate/glutamate-positive (Leranth et al., 1999). Supramammillary neurons projecting to the MS/DB are calretinin and aspartate/glutamate-positive (Leranth and Kiss, 1996). Interestingly, the CR-containing neurons of the triangular septal nucleus send projections to the medial habenula and their terminals are characterized as displaying round vesicles and asymmetric contacts that are associated with excitatory transmission (Sperlagh et al., 1998).

\section{Parcellation of the MS and neurons projecting to the NI}

The MS/DB consists of distinct neuronal groups in subregions of the MS, VDB, and HDB and in a recent study we observed that neurons at the border between the medial and lateral septal areas project to the hypothalamus (Olucha-Bordonau et al., 2012). In the current study, we observed that neurons within the VDB and MS that project to the $\mathrm{NI}$ are dispersed within these regions. In contrast, neurons in the HDB that project to the $\mathrm{NI}$ are ChAT-negative and reside in a deeper region near adjacent to cholinergic neurons that are located more superficially and presumably project to the hippocampus, amygdala, and cortex (Senut et al., 1989).

Wouterlood et al. (1988) observed that MS/DB projections to hypothalamic histaminergic neuron populations are arranged in a similar pattern, whereby anterograde tracer injections progressively targeting the midline of the septum resulted in decreased labeling of fibers and varicosities on histaminergic neurons. Accordingly, a strip-like organization of the MS/DB has also been recently documented (Tsurusaki and Gallagher, 2006), where noncholinergic, midline MS neurons display a distinct electrophysiological activity to that of more laterally located MS neurons. Interestingly, projections from a lateral strip of the MS innervate a hypothalamic region underlying aggressive behavior (Roeling et al., 1994). Together, these findings further confirm the complexity of the heterogeneous MS/DB anatomical connectivity (Peterson, 1994; Kiss et al., 1997) and provide a better structural basis on which to explore its functional roles.

\section{Posterior septal projections to NI}

The present data regarding posterior septal projections to $\mathrm{NI}$ highlight the likely role of the septohabenula-interpeduncular axis in modulating $\mathrm{NI}$ function. Currently, there are only a few reports focused on the efferent projections of the posterior septum, but there is a consensus that the posterior septum is the origin of the stria medullaris projection to the habenula, 
which, in turn, projects to the interpeduncular nuclei through the fasciculus retroflexus. All these structures are targeted by projections from the $\mathrm{NI}$ (Goto et al., 2001; Olucha-Bordonau et al., 2003) and all display retrograde labeling after retrograde tracer injections into the $\mathrm{NI}$ (Goto et al., 2001). The triangular septal nucleus is a major source of the purinergic innervation of the habenula (Sperlagh et al., 1998). In addition, tracer injections in the septofimbrial nucleus also resulted in anterograde labeling in the MS/DB and supramammillary nucleus (Risold and Swanson, 1997), two components of the well-known ascending system controlling theta rhythm (McNaughton et al., 1995; Pan and McNaughton, 1997; Vertes and Kocsis, 1997).

The posterior septum also moderates processes in which the NI plays an important role through neural structures that are also targeted by the NI. In this respect, it has recently been shown that triangular septal projections to the medial habenula and from there to the interpeduncular nuclei are involved in modulation of anxiety processes (Yamaguchi et al., 2013). All these structures are innervated by the NI (Goto et al., 2001; Olucha-Bordonau et al., 2003). Moreover, central administration of a relaxin-3 agonist, a neuropeptide produced by NI neurons, induces anxiolytic and antidepressive behaviors in the plus maze and forced swim tests (Ryan et al., 2013).

It is also important to consider the putative projection from the posterior septum to surrounding areas of the NI. We observed anterograde labeling in the PDTg, LDTg, and Barrington's nucleus after anterograde tracer injections into the posterior septum. These projections seem to be parallel to the projections arising from the mammillary complex. The dorsal tegmental nuclei have bidirectional projections with the lateral mammillary nucleus (Hayakawa and Zyo, 1989, 1990), which are related to head orientation movements (Blair et al., 1997). Notably, in the context of NI function and its role in theta rhythm regulation, there is a close relationship between theta rhythm and head movements (Brandon et al., 2013).

\section{Hippocampal theta rhythmogenesis via bidirectional pathways}

Extensive research has revealed a central role for ascending subcortico-hippocampal projections in driving hippocampal theta rhythm (see Vertes and Kocsis, 1997, for review). Importantly, brainstem-elicited theta activity stemming from the nucleus RPO is mediated by a series of ascending projections principally involving the median raphe nucleus, supramammillary nucleus, and MS/DB (Peterson, 1994), whereby each node is thought to primarily regulate a specific aspect of hippocampal theta rhythm (Nunez et al., 1991; Vertes et al., 1993). The median raphe is involved in the desynchronization of theta activity (Kinney et al., 1994, 1995; Vertes et al., 1994; Kocsis and Vertes, 1996; Viana Di Prisco et al., 2002); the supramammillary nucleus modulates theta frequency (McNaughton et al., 1995; Kocsis and Vertes, 1997; Pan and McNaughton, 1997); and the MS is considered the pacemaker of theta activity (Nerad and McNaughton, 2006; Varga et al., 2008; Hangya et al., 2009).

Other research has challenged this view, particularly the latter role of MS as pacemaker of theta activity, as Nerad and McNaughton (2006) observed a number of discrepancies in the synchrony between these various nuclei in studies of freely moving rats and postulated that the hippocampal theta "pacemaker" is more likely "a set of functionally differentiated components rather than a single homogenous unit." In agreement with this hypothesis, the findings of the present study reveal a novel pathway involving descending projections from the MS/DB to the NI which may be functionally linked to the hippocampus septal projection. Previous studies also revealed that MS CR neurons provide descending projections to the supramammillary nucleus (Borhegyi and Freund, 1998). Notably, septal CR-containing neurons also receive descending projections from the entorhinal cortex (Leranth et al., 1999). The CR-positive MS/DB to NI pathway described shares this important feature with the septum to supramammillary connection (Borhegyi and Freund, 1998; Leranth et al., 1999). Future studies will investigate whether descending projections from the MS/DB to the supramammillary nucleus and $\mathrm{NI}$ arise from different populations of neurons or are collaterals of the same neurons.

The proposed circuitry suggests a high degree of complexity in the generation and modulation of theta, and, therefore, we postulate that this newly identified circuitry provides a means for fine-tuning hippocampal rhythms and that the reciprocal ascending-descending pathways may provide a system for "auto-adjustment," which is the basis for the high coherence between the firing of $\mathrm{NI}$ neurons, in particular those containing relaxin-3, and hippocampal theta rhythm (Ma et al., 2013).

\section{Implications of bidirectional NI-septum connections for behavioral control}

The neural projections from MS/DB and posterior septum to NI target GABAergic neurons in NI and represent a newly identified influence on telencephalic centers. The MS/DB participates in modulation of a range of functions anatomically and functionally associated 
with other brain centers. For example, lesions or reversible inactivation of the MS/DB in rats has been shown to be anxiolytic, since it decreased activity in the shock-probe burying test (Menard and Treit, 1996) and increased open arm exploration in the elevated plus maze (Lamprea et al., 2010). Therefore, the NI, which can influence activity within the MS and the overall activity of the septohippocampal system (Nunez et al., 2006; Ma et al., 2009b) may have a role in modulating circuits that control anxiety-related behaviors. Similarly, the present data suggest that the MS/DB and posterior septum to $\mathrm{NI}$ projection may contribute to the overall $\mathrm{NI}$ effect on the major telencephalic centers controlling anxiety (Ryan et al., 2011). Alterations in NI activity by MS or posterior septum descending projections may then affect activity of other telencephalic centers innervated by NI, such as the prefrontal cortex (Farooq et al., 2013).

McNaughton and Gray (2000) proposed that the septohippocampal pathway is the core component of the "behavioral inhibition system." This theory proposes that the "behavioral inhibition system" compares actual events occurring with those expected, and when there is a mismatch between them, this system/circuit produces an output to halt the current motor program and possibly reduce the activity in the future. In line with this view, the septohippocampal pathway, acting as a behavioral inhibition system, would respond to unexpected external signals that could potentially be a threat. In such a scenario, the actions of the septohippocampal pathway could lead to anxiety.

However, significant evidence confirms a role of the MS/DB and septohippocampal interactions in exploration, spatial navigation, and object recognition (Poucet, 1989; Poucet and Buhot, 1994; Okada and Okaichi, 2010). The occurrence of descending projections from the MS/DB to the $\mathrm{NI}$ and the ascending connections from the $\mathrm{NI}$ to the hippocampus represents a neural loop that may act as a whole to generate a cognitive internal and external map. Specific disruption of relaxin-3 projections from the $\mathrm{NI}$ to the MS, by local septal infusion of RXFP3 antagonist, resulted in impairment of spatial working memory in the spontaneous alternation test (Ma et al., 2009b). In light of the present results, these data could be interpreted not only as a disruption of the septohippocampal pathway, but the disruption of the septo-incertushippocampus pathway, or more likely both networks. The autoregulatory effect between the MS and the $\mathrm{NI}$ may also impinge on other inter-telencephalic connections. It has been reported that $\mathrm{NI}$ stimulation results in inhibition of firing in the prefrontal cortex, and stimulation of the $\mathrm{NI}$ or local corticotropin-releasing hormone (CRH) infusion, block long-term potentiation induced by tetanus stimulation in ventral hippocampus (Farooq et al., 2013).

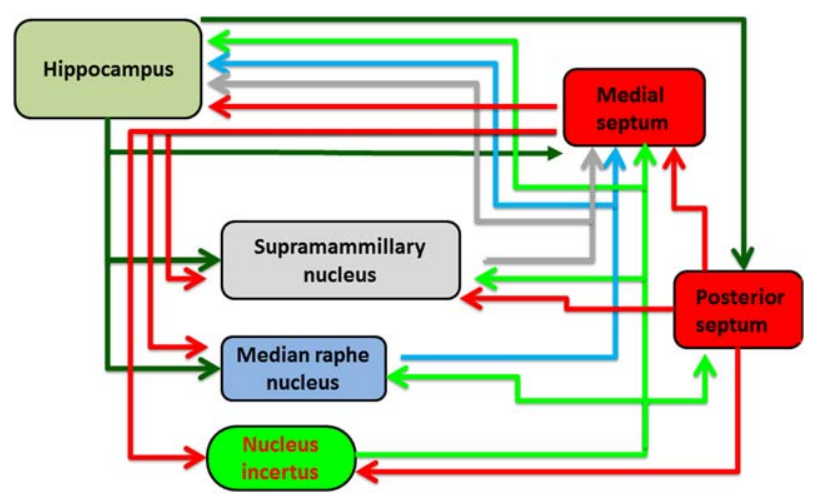

Figure 13. Schematic model of the putative hippocampusseptum-nucleus incertus circuit. This model incorporates the wellcharacterized ascending projections from the $\mathrm{NI}$ to the septum and hippocampus and the newly identified descending projection from the septum to the hypothalamus, median raphe, and $\mathrm{NI}$, which represent a reciprocal neural loop. Essentially, the septum provides descending projections/inputs to hypothalamic nuclei, brainstem, and the $\mathrm{Nl}$; all these areas, in turn, provide ascending innervations/inputs to the hippocampus. As the septum receives projections from all these nuclei, our data suggest an anatomical basis for a neural feedback to regulate septal function. [Color figure can be viewed in the online issue, which is available at wileyonlinelibrary.com.]

It is also important to note the different roles that descending projections from MS/DB may play in regulating $\mathrm{NI}$ activity, as MS/VDB mainly projects to the hippocampus and HDB projects mainly to the amygdala (Woolf and Butcher, 1982). Thus, a pathway may exist from the $\mathrm{HDB}$ to the NI, which also controls the amygdala, and in turn the NI projects to the ventral hippocampus. In this case, the ventral hippocampus is more closely related to emotional aspects of cognition such as the extinction of fear memory (Hobin et al., 2006; Ji and Maren, 2007; Sierra-Mercado et al., 2011; Kheirbek et al., 2013) and this process is context-dependent and related to ventral hippocampus connections to the prefrontal cortex and amygdala (Ishikawa and Nakamura, 2006).

\section{CONCLUSION}

This study describes descending projections from the MS/DB and posterior septum to the NI, which may represent the neural substrate for feedback to the ascending NI projections to the MS/DB and hippocampus that regulate hippocampal theta rhythm (Fig. 13). Evidence from tracing their neural connections demonstrates that all components of the ascending projections to the hippocampus are bidirectionally connected, some of them by inhibitory systems, which raises the possibility of an autoregulatory system that adjusts firing patterns as a 
result of overlapping projections at each node of the network. This system may be associated with the observed phase-locking between the hippocampal field potential and NI neural firing (Ma et al., 2013), but additional experiments are now required to understand the role of the descending septum-NI pathway in modulating hippocampal and other telencephalic areas targeted by widespread NI GABAergic/peptidergic projections.

\section{ACKNOWLEDGMENTS}

The authors acknowledge the support of the A. Koplowitz Foundation for providing a Training Fellowship for A.M.S.-P. to undertake studies at the Florey Institute of Neuroscience and Mental Health.

\section{CONFLICT OF INTEREST}

All authors declare that there is no potential conflict of interest including any financial, personal, or other relationships with other people or organizations that could inappropriately influence, or be perceived to influence, their work.

\section{ROLE OF AUTHORS}

All authors had full access to all the data in the study and take responsibility for the integrity of the data and the accuracy of the data analysis. Study concept and design: Sánchez-Pérez AM, Olucha-Bordonau FE. Acquisition of data: Sánchez-Pérez AM, Arnal-Vicente I, Santos FN, Pereira CW. Analysis and interpretation of data: Sánchez-Pérez AM, EIMlili N, Olucha-Bordonau FE. Drafting of the article: Sánchez-Pérez AM, OluchaBordonau FE. Critical revision of the article for important intellectual content: Sánchez-Pérez AM, Olucha-Bordonau FE, Sanjuan J, Ma S, Gundlach AL. Obtained funding: Sánchez-Pérez AM, Sanjuan J, Olucha-Bordonau FE, Gundlach AL. Administrative, technical, and material support: Arnal-Vicente I. Study supervision: Sánchez-Pérez AM, Gundlach AL, Olucha-Bordonau FE.

\section{LITERATURE CITED}

Airaksinen MS, Eilers J, Garaschuk O, Thoenen H, Konnerth A, Meyer M. 1997. Ataxia and altered dendritic calcium signaling in mice carrying a targeted null mutation of the calbindin D28k gene. Proc Natl Acad Sci U S A 94: 1488-1493.

Apartis E, Poindessous-Jazat FR, Lamour YA, Bassant MH. 1998. Loss of rhythmically bursting neurons in rat medial septum following selective lesion of septohippocampal cholinergic system. J Neurophysiol 79:1633-1642.

Behzadi G, Kalen P, Parvopassu F, Wiklund L. 1990. Afferents to the median raphe nucleus of the rat: retrograde cholera toxin and wheat germ conjugated horseradish peroxidase tracing, and selective D- $\left[{ }^{3} \mathrm{H}\right]$ aspartate labeling of possible excitatory amino acid inputs. Neuroscience 37:77-100.

Biancardi VC, Campos RR, Stern JE. 2010. Altered balance of gamma-aminobutyric acidergic and glutamatergic afferent inputs in rostral ventrolateral medulla-projecting neurons in the paraventricular nucleus of the hypothalamus of renovascular hypertensive rats. J Comp Neurol 518:567-585.

Blair HT, Lipscomb BW, Sharp PE. 1997. Anticipatory time intervals of head-direction cells in the anterior thalamus of the rat: implications for path integration in the headdirection circuit. J Neurophysiol 78:145-159.

Borhegyi Z, Freund TF. 1998. Dual projection from the medial septum to the supramammillary nucleus in the rat. Brain Res Bull 46:453-459.

Brandon MP, Bogaard AR, Schultheiss NW, Hasselmo ME. 2013. Segregation of cortical head direction cell assemblies on alternating theta cycles. Nat Neurosci 16:739748.

Celio MR, Baier W, Scharer L, de Viragh PA, Gerday C. 1988. Monoclonal antibodies directed against the calcium binding protein parvalbumin. Cell Calcium 9:81-86.

Celio MR, Baier W, Scharer L, Gregersen HJ, de Viragh PA, Norman AW. 1990. Monoclonal antibodies directed against the calcium binding protein calbindin D-28k. Cell Calcium 11:599-602.

Cornwall J, Cooper JD, Phillipson OT. 1990. Afferent and efferent connections of the laterodorsal tegmental nucleus in the rat. Brain Res Bull 25:271-284.

Dwyer TA, Servatius RJ, Pang KC. 2007. Noncholinergic lesions of the medial septum impair sequential learning of different spatial locations. J Neurosci 27:299-303.

Farooq U, Rajkumar R, Sukumaran S, Wu Y, Tan WH, Dawe GS. 2013. Corticotropin-releasing factor infusion into nucleus incertus suppresses medial prefrontal cortical activity and hippocampo-medial prefrontal cortical longterm potentiation. Eur J Neurosci 38:2516-2525.

Freund TF, Gulyas Al. 1997. Inhibitory control of GABAergic interneurons in the hippocampus. Can J Physiol Pharmacol 75:479-487.

Freund TF, Antal M. 1988. GABA-containing neurons in the septum control inhibitory interneurons in the hippocampus. Nature 336:170-173.

Goto M, Swanson LW, Canteras NS. 2001. Connections of the nucleus incertus. J Comp Neurol 438:86-122.

Hangya B, Borhegyi Z, Szilagyi N, Freund TF, Varga V. 2009. GABAergic neurons of the medial septum lead the hippocampal network during theta activity. J Neurosci 29: 8094-8102.

Hayakawa T, Zyo K. 1989. Retrograde double-labeling study of the mammillothalamic and the mammillotegmental projections in the rat. J Comp Neurol 284:1-11.

Hayakawa T, Zyo K. 1990. Fine structure of the lateral mammillary projection to the dorsal tegmental nucleus of Gudden in the rat. J Comp Neurol 298:224-236.

Hobin JA, Ji J, Maren S. 2006. Ventral hippocampal muscimol disrupts context-specific fear memory retrieval after extinction in rats. Hippocampus 16:174-182.

Ishikawa A, Nakamura S. 2006. Ventral hippocampal neurons project axons simultaneously to the medial prefrontal cortex and amygdala in the rat. J Neurophysiol 96:2134-2138.

Kesner RP, Crutcher KA, Measom MO. 1986. Medial septal and nucleus basalis magnocellularis lesions produce order memory deficits in rats which mimic symptomatology of Alzheimer's disease. Neurobiol Aging 7:287-295.

Kinney GG, Kocsis B, Vertes RP. 1994. Injections of excitatory amino acid antagonists into the median raphe nucleus produce hippocampal theta rhythm in the urethaneanesthetized rat. Brain Res 654:96-104.

Kinney GG, Kocsis B, Vertes RP. 1995. Injections of muscimol into the median raphe nucleus produce hippocampal theta rhythm in the urethane anesthetized rat. Psychopharmacology (Berl) 120:244-248. 
Kiss J, Borhegyi Z, Csaky A, Szeiffert G, Leranth C. 1997. Parvalbumin-containing cells of the angular portion of the vertical limb terminate on calbindin-immunoreactive neurons located at the border between the lateral and medial septum of the rat. Exp Brain Res 113:48-56.

Kocsis B, Vertes RP. 1997. Phase relations of rhythmic neuronal firing in the supramammillary nucleus and mammillary body to the hippocampal theta activity in urethane anesthetized rats. Hippocampus 7:204-214.

Kocsis B, Vertes RP. 1996. Midbrain raphe cell firing and hippocampal theta rhythm in urethane-anaesthetized rats. Neuroreport 7:2867-2872.

Krayniak PF, Weiner S, Siegel A. 1980. An analysis of the efferent connections of the septal area in the cat. Brain Res 189:15-29.

Lee MG, Chrobak JJ, Sik A, Wiley RG, Buzsaki G. 1994. Hippocampal theta activity following selective lesion of the septal cholinergic system. Neuroscience 62:1033-1047.

Leranth C, Kiss J. 1996. A population of supramammillary area calretinin neurons terminating on medial septal area cholinergic and lateral septal area calbindin-containing cells are aspartate/glutamatergic. J Neurosci 16:76997710 .

Leranth C, Vertes RP. 1999. Median raphe serotonergic innervation of medial septum/diagonal band of broca (MSDB) parvalbumin-containing neurons: possible involvement of the MSDB in the desynchronization of the hippocampal EEG. J Comp Neurol 410:586-598.

Leranth C, Carpi D, Buzsaki G, Kiss J. 1999. The entorhinosepto-supramammillary nucleus connection in the rat: morphological basis of a feedback mechanism regulating hippocampal theta rhythm. Neuroscience 88:701-718.

Ma S, Bonaventure $\mathrm{P}$, Ferraro $\mathrm{T}$, Shen PJ, Burazin TCD, Bathgate RAD, Liu C, Tregear GW, Sutton SW, Gundlach AL. 2007. Relaxin-3 in GABA projection neurons of nucleus incertus suggests widespread influence on forebrain circuits via G-protein-coupled receptor-135 in the rat. Neuroscience 144:165-190.

Ma S, Shen PJ, Sang Q, Lanciego JL, Gundlach AL. 2009a. Distribution of relaxin-3 mRNA and immunoreactivity and RXFP3-binding sites in the brain of the macaque, Macaca fascicularis. Ann N Y Acad Sci 1160:256-258.

Ma S, Olucha-Bordonau FE, Hossain MA, Lin F, Kuei C, Liu C, Wade JD, Sutton SW, Nunez A, Gundlach AL. 2009b. Modulation of hippocampal theta oscillations and spatial memory by relaxin-3 neurons of the nucleus incertus. Learn Mem 16:730-742.

Ma S, Blasiak A, Olucha-Bordonau FE, Verberne AJ, Gundlach AL. 2013. Heterogeneous responses of nucleus incertus neurons to corticotrophin-releasing factor and coherent activity with hippocampal theta rhythm in the rat. J Physiol 591:3981-4001.

Manseau F, Goutagny R, Danik M, Williams S. 2008. The hippocamposeptal pathway generates rhythmic firing of GABAergic neurons in the medial septum and diagonal bands: an investigation using a complete septohippocampal preparation in vitro. J Neurosci 28:4096-4107.

McNaughton N, Logan B, Panickar KS, Kirk IJ, Pan WX, Brown NT, Heenan A. 1995. Contribution of synapses in the medial supramammillary nucleus to the frequency of hippocampal theta rhythm in freely moving rats. Hippocampus 5:534-545.

Moruzzi G, Magoun HW. 1995. Brain stem reticular formation and activation of the EEG. 1949. J Neuropsychiatry Clin Neurosci 7:251-267.

Nerad L, McNaughton N. 2006. The septal EEG suggests a distributed organization of the pacemaker of hippocampal theta in the rat. Eur J Neurosci 24:155-166.
Nunez A, de Andres I, Garcia-Austt E. 1991. Relationships of nucleus reticularis pontis oralis neuronal discharge with sensory and carbachol evoked hippocampal theta rhythm. Exp Brain Res 87:303-308.

Nunez A, Cervera-Ferri A, Olucha-Bordonau F, Ruiz-Torner A, Teruel V. 2006. Nucleus incertus contribution to hippocampal theta rhythm generation. Eur J Neurosci 23: 2731-2738.

Okada K, Okaichi H. 2010. Functional cooperation between the hippocampal subregions and the medial septum in unreinforced and reinforced spatial memory tasks. Behav Brain Res 209:295-304.

Olucha-Bordonau FE, Teruel V, Barcia-Gonzalez J, Ruiz-Torner A, Valverde-Navarro AA, Martinez-Soriano F. 2003. Cytoarchitecture and efferent projections of the nucleus incertus of the rat. J Comp Neurol 464:62-97.

Pan WX, McNaughton N. 1997. The medial supramammillary nucleus, spatial learning and the frequency of hippocampal theta activity. Brain Res 764:101-108.

Paxinos G, Watson C. 2014. The rat brain in stereotaxic coordinates. San Diego: Academic Press.

Peterson GM. 1994. Differential projections to the hippocampus by neurons of the medial septum and vertical limb of the diagonal band. Brain Res 646:129-134.

Petsche H, Stumpf C. 1962. The origin of theta-rhytm in the rabbit hippocampus. Wien Klin Wochenschr 74:696-700.

Poucet B. 1989. Object exploration, habituation, and response to a spatial change in rats following septal or medial frontal cortical damage. Behav Neurosci 103:10091016.

Poucet B, Buhot MC. 1994. Effects of medial septal or unilateral hippocampal inactivations on reference and working spatial memory in rats. Hippocampus 4:315-321.

Rico B, Cavada C. 1998. Adrenergic innervation of the monkey thalamus: an immunohistochemical study. Neuroscience 84:839-847.

Risold PY. 2004. The septal region. In: Paxinos G, editor. The rat nervous system. San Diego: Elsevier. p 605-632.

Risold PY, Swanson LW. 1997. Connections of the rat lateral septal complex. Brain Res Brain Res Rev 24:115-195.

Roeling TA, Veening JG, Kruk MR, Peters JP, Vermelis ME, Nieuwenhuys R. 1994. Efferent connections of the hypothalamic "aggression area" in the rat. Neuroscience 59: 1001-1024.

Ryan PJ, Ma S, Olucha-Bordonau FE, Gundlach AL. 2011. Nucleus incertus An emerging modulatory role in arousal, stress and memory. Neurosci Biobehav Rev 35:1326-1341.

Ryan PJ, Buchler E, Shabanpoor F, Hossain MA, Wade JD, Lawrence AJ, Gundlach AL. 2013. Central relaxin-3 receptor (RXFP3) activation decreases anxiety- and depressive-like behaviours in the rat. Behav Brain Res 244:142- 151.

Sainsbury RS, Bland BH. 1981. The effects of selective septal lesions on theta production in CA1 and the dentate gyrus of the hippocampus. Physiol Behav 26:1097-1101.

Schurmans S, Schiffmann SN, Gurden H, Lemaire M, Lipp HP, Schwam V, Pochet R, Imperato A, Bohme GA, Parmentier M. 1997. Impaired long-term potentiation induction in dentate gyrus of calretinin-deficient mice. Proc Natl Acad Sci U S A 94:10415-10420.

Schwaller B, Tetko IV, Tandon P, Silveira DC, Vreugdenhil M, Henzi T, Potier MC, Celio MR, Villa AE. 2004. Parvalbumin deficiency affects network properties resulting in increased susceptibility to epileptic seizures. Mol Cell Neurosci 25:650-663.

Senut MC, Menetrey D, Lamour Y. 1989. Cholinergic and peptidergic projections from the medial septum and the nucleus of the diagonal band of Broca to dorsal 
hippocampus, cingulate cortex and olfactory bulb: a combined wheatgerm agglutinin-apohorseradish peroxidasegold immunohistochemical study. Neuroscience 30:385403.

Sierra-Mercado D, Padilla-Coreano N, Quirk GJ. 2011. Dissociable roles of prelimbic and infralimbic cortices, ventral hippocampus, and basolateral amygdala in the expression and extinction of conditioned fear. Neuropsychopharmacology 36:529-538.

Smith CM, Shen PJ, Banerjee A, Bonaventure P, Ma S, Bathgate RA, Sutton SW, Gundlach AL. 2010. Distribution of relaxin-3 and RXFP3 within arousal, stress, affective, and cognitive circuits of mouse brain. J Comp Neurol 518:4016-4045.

Sotty F, Danik M, Manseau F, Laplante F, Quirion R, Williams S. 2003. Distinct electrophysiological properties of glutamatergic, cholinergic and GABAergic rat septohippocampal neurons: novel implications for hippocampal rhythmicity. J Physiol 551:927-943.

Sperlagh B, Magloczky Z, Vizi ES, Freund TF. 1998. The triangular septal nucleus as the major source of ATP release in the rat habenula: a combined neurochemical and morphological study. Neuroscience 86:1195-1207.

Swanson LW, Cowan WM. 1979. The connections of the septal region in the rat. J Comp Neurol 186:621-655.

Tanaka M, lijima N, Miyamoto Y, Fukusumi S, Itoh Y, Ozawa H, Ibata Y. 2005. Neurons expressing relaxin 3/INSL 7 in the nucleus incertus respond to stress. Eur J Neurosci 21:1659-1670.

Toth K, Freund TF, Miles R. 1997. Disinhibition of rat hippocampal pyramidal cells by GABAergic afferents from the septum. J Physiol 500(Pt 2):463-474.

Tsurusaki M, Gallagher JP. 2006. A distinct group of noncholinergic neurons along the mid-line of the septum and within the rat medial septal nucleus. Neurosci Lett 410: $20-24$.

Varga V, Hangya B, Kranitz K, Ludanyi A, Zemankovics R, Katona I, Shigemoto R, Freund TF, Borhegyi Z. 2008. The presence of pacemaker $\mathrm{HCN}$ channels identifies theta rhythmic GABAergic neurons in the medial septum. J Physiol 586:3893-3915.

Vertes RP. 1981. An analysis of ascending brain stem systems involved in hippocampal synchronization and desynchronization. J Neurophysiol 46:1140-1159.
Vertes RP. 1982. Brain stem generation of the hippocampal EEG. Prog Neurobiol 19:159-186.

Vertes RP, Kocsis B. 1997. Brainstem-diencephalo-septohippocampal systems controlling the theta rhythm of the hippocampus. Neuroscience 81:893-926.

Vertes RP, Colom LV, Fortin WJ, Bland BH. 1993. Brainstem sites for the carbachol elicitation of the hippocampal theta rhythm in the rat. Exp Brain Res 96:419-429.

Vertes RP, Kinney GG, Kocsis B, Fortin WJ. 1994. Pharmacological suppression of the median raphe nucleus with serotonin $1 \mathrm{~A}$ agonists, 8-OH-DPAT and buspirone, produces hippocampal theta rhythm in the rat. Neuroscience 60:441-451.

Viana Di Prisco G, Albo Z, Vertes RP, Kocsis B. 2002. Discharge properties of neurons of the median raphe nucleus during hippocampal theta rhythm in the rat. Exp Brain Res 145:383-394.

Winson J. 1978. Loss of hippocampal theta rhythm results in spatial memory deficit in the rat. Science 201:160163.

Woolf NJ, Butcher LL. 1982. Cholinergic projections to the basolateral amygdala: a combined Evans Blue and acetylcholinesterase analysis. Brain Res Bull 8:751-763.

Wouterlood FG, Gaykema RP, Steinbusch HW, Watanabe T, Wada H. 1988. The connections between the septumdiagonal band complex and histaminergic neurons in the posterior hypothalamus of the rat. Anterograde tracing with Phaseolus vulgaris-leucoagglutinin combined with immunocytochemistry of histidine decarboxylase. Neuroscience 26:827-845.

Yamaguchi T, Danjo T, Pastan I, Hikida T, Nakanishi S. 2013. Distinct roles of segregated transmission of the septo-habenular pathway in anxiety and fear. Neuron 78:537-544.

Yoder RM, Pang KC. 2005. Involvement of GABAergic and cholinergic medial septal neurons in hippocampal theta rhythm. Hippocampus 15:381-392.

Zhang H, Lin SC, Nicolelis MA. 2011. A distinctive subpopulation of medial septal slow-firing neurons promote hippocampal activation and theta oscillations. J Neurophysiol 106:2749-2763.

Zimmermann L, Schwaller B. 2002. Monoclonal antibodies recognizing epitopes of calretinins: dependence on Ca2+-binding status and differences in antigen accessibility in colon cancer cells. Cell Calcium 31:13-25. 